\title{
Shift from Gel Based to Gel Free Proteomics to Unlock Unknown Regulatory Network in Plants: A Comprehensive Review
}

\author{
Sajad Majeed Zargar ${ }^{1 *}$, Nancy Gupta ${ }^{2}$, Rakeeb A Mir ${ }^{3}$, Vandna Rai ${ }^{4}$ \\ ${ }^{1}$ Centre for Plant Biotechnology, Division of Biotechnology, Sher-e-Kashmir University of Agricultural Sciences \& Technology of Kashmir, Shalimar, Srinagar, \\ $J \& K$, India \\ ${ }^{2}$ School Biotechnology, Sher-e-Kashmir University of Agricultural Sciences \& Technology of Jammu, Chatha, Jammu, J\&K, India \\ ${ }^{3}$ School of Bio resources \& Biotechnology, BGSB University, Rajouri, J\&K, India \\ ${ }^{4} \mathrm{NRCPB}$, New Delhi, India
}

Received: March 23, 2016; Accepted: April 17, 2016; Published: April 28, 2016

*Corresponding author: Sajad Majeed Zargar, Centre for Plant Biotechnology, Division of Biotechnology, Sher-e-Kashmir University of Agricultural Sciences \& Technology of Kashmir, Shalimar, Srinagar, J\&K, India, E-mail: smzargar@gmail.com

\begin{abstract}
Proteomics has emerged as a vital tool to identify the novel proteins and explore the cellular dynamics by employing highly proficient and innovative techniques introduced in the past few years. The expedition began with the emergence of gel-based 2DE approaches for evaluation of diverse proteins and differential protein analysis. Later, advancements in the field lead to the advent of gel-free approaches that render more accuracy and reliable results. In spite of introduction of high-throughput analysis offered by new techniques, the overall beneficence of gel-based approaches cannot be ignored. The combined effort of all these approaches can generate astonishing results. Protein analysis under specific conditions attempts to deduce the expression pathways and thus will help to expand our knowledge pertaining to metabolic and regulatory routes. Further, understanding the dynamics of these biomolecules and metabolites involved in the pathways can facilitate their desired manipulation for altering the gene expression. This will assist in clinical purposes for development of drugs and in systems biology to get the broad picture of metabolic processes and their regulation. This review highlights the trend with which progress in plant proteomics technology has been made right from gel based to gel free strategies with discussion of basic principles and procedures involved in each technique. Advances in this field can lead to precise interpretation of several biological processes.
\end{abstract}

Keywords: 2DE; DIGE; iTRAQ; ICAT; SILAC; plant proteomics; quantitative proteomics

\section{Introduction}

Proteomics refers to the high throughput systematic analysis of protein expression and function with the aid of protein biochemistry, mass spectrometry and bioinformatics' tools. Most of the biological researches aim to decipher the metabolic regulatory pathways to gain deeper insight into various cellular processes and thus contributing to our understanding of biological systems. Although, there are ongoing efforts to gather information contained in the human genome sequence through genomics and transcriptomics approaches; elucidating the dynamic changes in proteins will provide a better picture of cellular genetics and its regulation. In this context, quantitative proteomics has been emerged recently as a fascinating platform to explore the hidden pathways and reveal fundamentals of biological systems. With the advent of the most feasible and spectacular techniques, quantitative proteomics is directed to exemplify the identification and quantification of diverse proteins that represent a rich source of biological information. Quantitative proteomics employs various techniques for separation of proteins based on their physicochemical properties (molecular mass, $\mathrm{pH}$, charge etc) followed by their recognition and quantification by mass spectrometry methods utilizing data systems and software's. The major steps involved in these analytical processes are i) cell sampling ii) extraction, isolation and solubilisation of proteins iii) separation through electrophoresis (isotachophoresis, zonal, isoelectric focussing, off gel) and chromatography (ion exchange chromatography, 2- dimensional liquid chromatography, reverse phase) iv) quantification using gel based and gel free approaches and v) identification using mass spectrometry approaches. The chief principles and procedure of aforementioned steps are briefly illustrated in (a,b,c,d,e). For detailed understanding of MS protein identification principles, readers are advised to visit http://www.spectroscopynow.com/ ; http://www.ionsource. com/; http://www.asms.org/whatisms/index.html. Many advances have been made so far in the field of quantitative proteomics, however there is no technique that demonstrates the actual expression of these biological entities (proteins) in one go as in case of genomics (microarray analysis, genome sequencing). Proteomics studies require the collective efforts of different fields of sciences (biochemistry, physics, computer sciences and statistics) that collaborate to analyse structural and functional aspects of proteins. In this review, we have highlighted various efficient and reliable quantification methods that differ in many ways in terms of progression, sensitivity, robustness, accuracy and quality of data obtained. Quantitative mass 
spectrometry approaches can be mainly categorized into gel based (2- dimensional electrophoresis) and gel-free approaches. Later are further divided to label-based (chemical, enzymatic and metabolic tagging) and label-free (data independent and data dependent) methods. Each technique has its pros and cons and rather than replacement, these methods complement each other. The choice of methodology adopted for analysis depends on the biological sample taken under consideration and the information required. In order to make successful systematic and quantitative profiling, we require good quality separation and quantitative techniques accompanied with protein/ nucleotide databases that promise high accuracy to search peptide masses with the assistance of powerful automated bioinformatic tools and softwares. Here, we have summarized the basic strategies involved in the aforementioned techniques that expedite the functional analysis of proteins on global scale and thus assisting the conventional molecular biology methods.

\section{Need for proteomics studies in plants}

Genes are considered to be the major repositories of biological information required for the processing of molecular mechanisms inside the cell. However, the information stored in the gene is in coded form and needs to be expressed and translated to proteins for performing vital functions of life. The genes are transcribed to mRNA in coded form of nucleotides that are further translated and decoded to amino acid sequence of proteins. Thus, for proper investigation of cellular processes, studies can be conducted at genomics (genes), transcriptomics (mRNA) and proteomics (protein) level. With the emergence of sequencing technique, it is possible to deduce the DNA sequence in short time but focus has now been shifted to predict the innumerable functions which are performed by the expression components of these genes i.e., Proteins. The study of cell at genomic and transcriptomic level provides a rough estimate of the expression and genome annotation. Thus study of proteins is important as these are the ultimate bio molecules that complement the structure and function of living systems. The concept of proteome was given by Marc Wilkins and his associates to describe the protein complement of the genome [1]. The large scale study of diverse proteins and precise measurement of their expression by utilizing powerful analytical techniques is referred to as "Proteomics" [2]. The wide acceptance of this recently emerged technology is attributed to advancements in the methodologies that attempt to accomplish accurate identification and quantification of proteins. The expression of genes can be detected by mRNA profiling but it neither reflects the correct amount of proteins nor their regulatory status [3]. Transcripts are highly unstable and are translated differently under varying environmental conditions producing different proteins. There is a dire need to analyse multiple protein products arising from single gene to figure out expression pathways thoroughly. Various post-translational modifications occur that affect the structure, localization and function of proteins and presents challenges in front of analytical tools to detect multiple forms of proteins [4]. A gene expressed under different set of environmental conditions generates separate transcripts which are further modified chemically and expressed in various ways to produce several forms of proteins. Thus, relying completely on genomics tools is not a good option. Expression studies should be carried out at proteome level to attain the complete knowledge of ongoing cellular processes. The first proteomic work in plants was published on evaluation of proteins in Arabidopsis thaliana using 2-dimensional gel electrophoresis [5]. The proteomic studies have made excellent progress in the past few years, right from the sub-cellular proteome expression analysis of various organelles [6-11]. And understanding the developmental process by spot comparison [12-14]. To deciphering the proteins involved in stress physiology [15-24] and plant pathogen interactions [25-28]. The detailed inspection of several proteins synthesized by various intriguing metabolic processes in relation to the external environment will help to assign functions to orphan genes and understanding their regulation ultimately serving the purpose. As proteins are directly involved in the molecular networks, accurate changes can be measured in response to alternating surroundings. Table 1 represents the key studies carried out on proteomic analysis of plants using advanced gel based and gel free methodologies. Thus, proteomics approaches can be considered as the essential key to unlock mysteries of life and its processes finally governing the efficient manipulation of pathways for improvement of crops.

\section{Proteomics Methodologies: Progress Till Date}

\section{Gel based methods}

Gel based protein separation and quantification is performed by integrating simple analytical methods of protein biochemistry with high throughput mass spectrometry analysis. The first report in this context was published about three decades ago by O'Farrel for analysis of complex proteins [68]. Since then, tremendous progress has been made in the field of protein studies due to continued development of methodologies in terms of precision and accuracy. This technique allows global analysis of thousands of protein isoforms expressing under specific set of conditions [4]. Gel based approach mainly employs 2D-PAGE (Two-dimensional polyacrylamide gel electrophoresis) and 2D-DIGE (Two dimensional differential gel electrophoresis) that efficiently separates proteins on the basis of their physicochemical properties, differentially analyses the spots obtained and finally identifies the components using mass spectrometry. Figure $2(\mathrm{a}, \mathrm{b})$ represents basic steps involved in gel based proteomics approach. In spite of huge advancements in the field of proteomics, these techniques have not been replaced and are routinely used for quantification of proteins.

2D-PAGE (Two Dimensional Polyacrylamide Gel Electrophoresis): Electrophoresis technique (separation of charged molecules under the influence of electric current) has been extensively utilized for the separation of biomolecules [69] based on their specific characteristics. Two dimensional approach attempts to separate proteins depending on two parameters i.e., $\mathrm{pH}$ and molecular mass. Former employs IEF (iso-electric focusing) technique and later utilizes polyacrylamide gels in electrolytic medium subjected to current under the influence of electric field. The second dimension represents better resolution and precision 


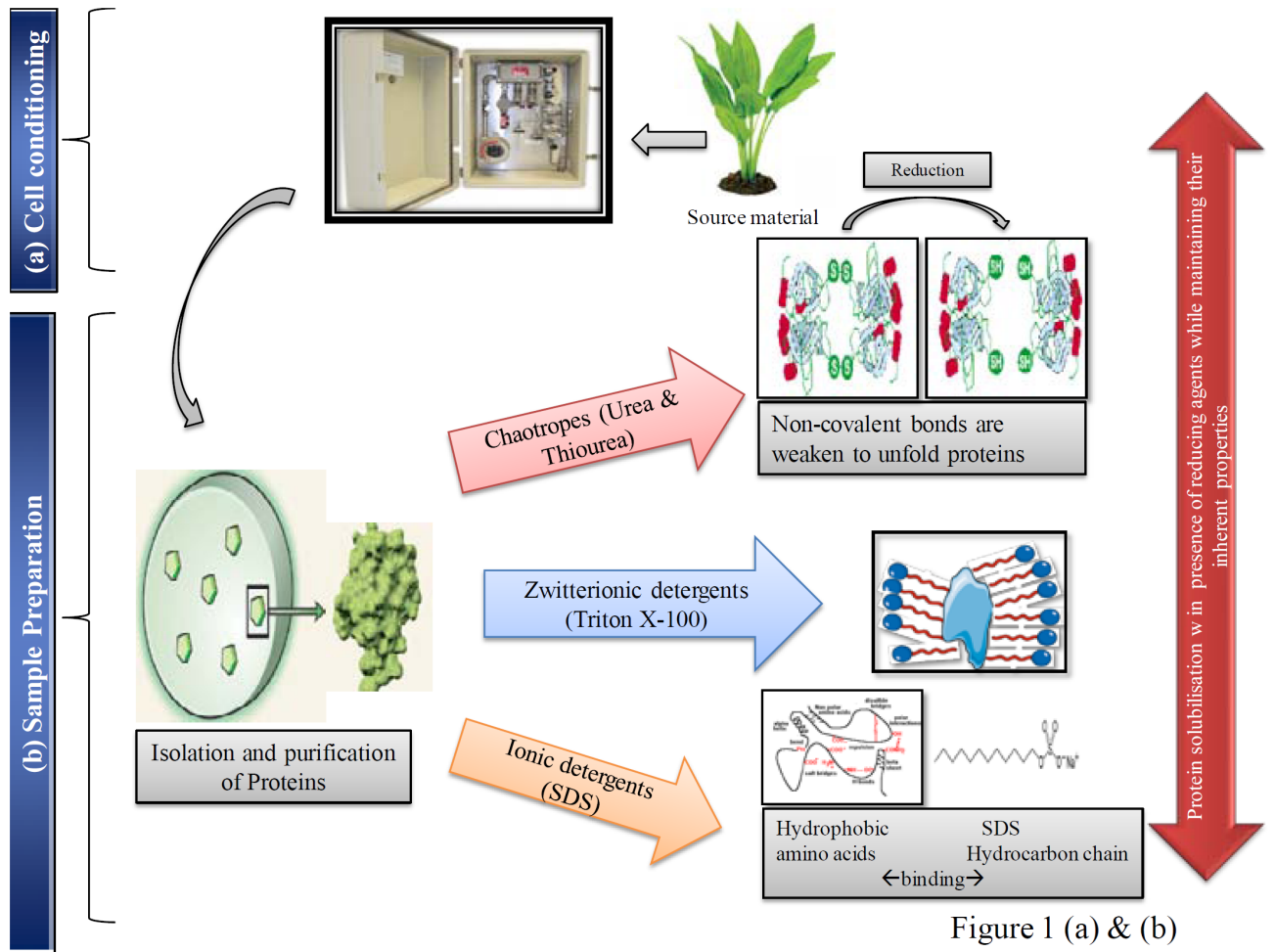

Figure 1ab: Major steps involved in proteomic analysis. (a) Cell conditioning; (b) Sample preparation.
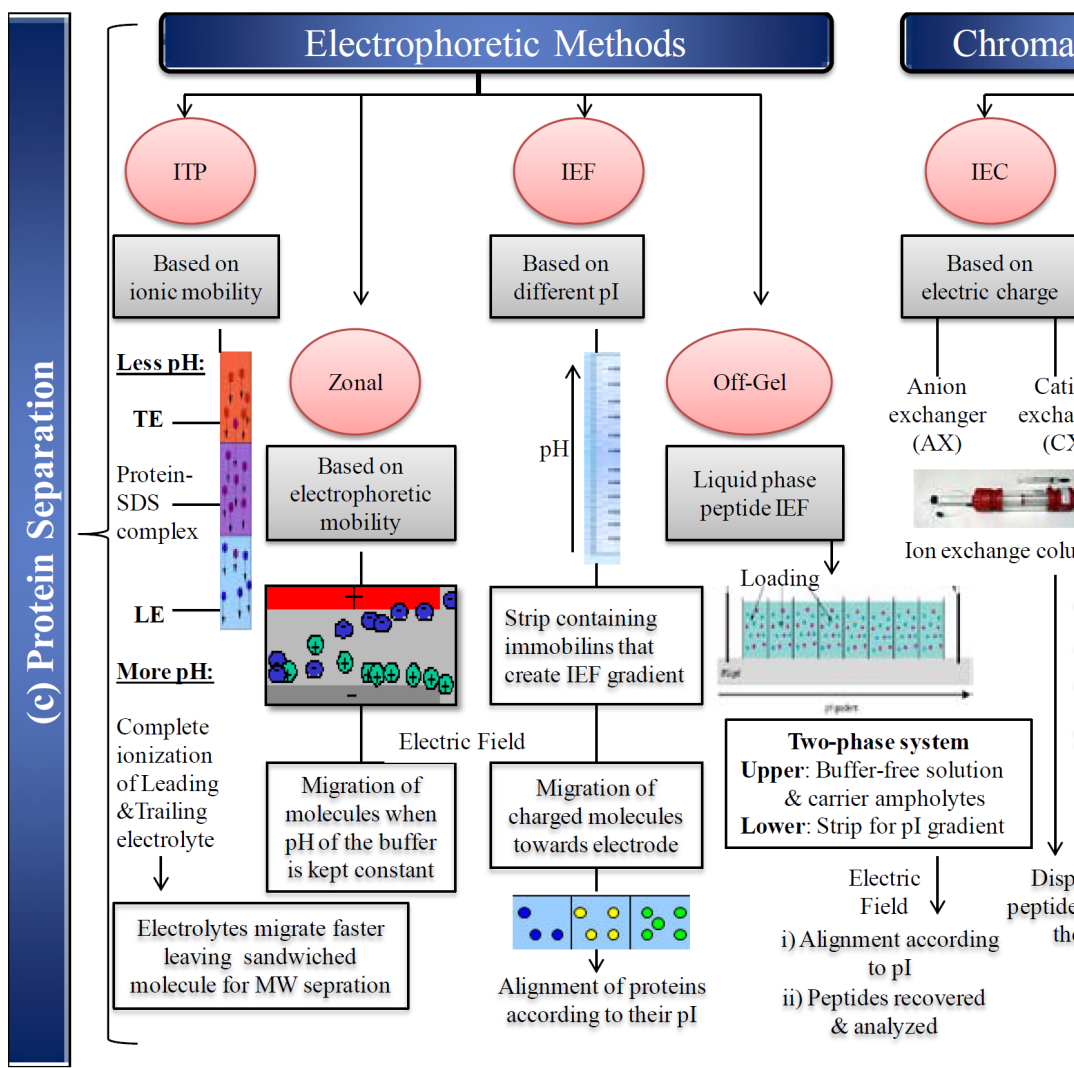

Chromatographic Methods
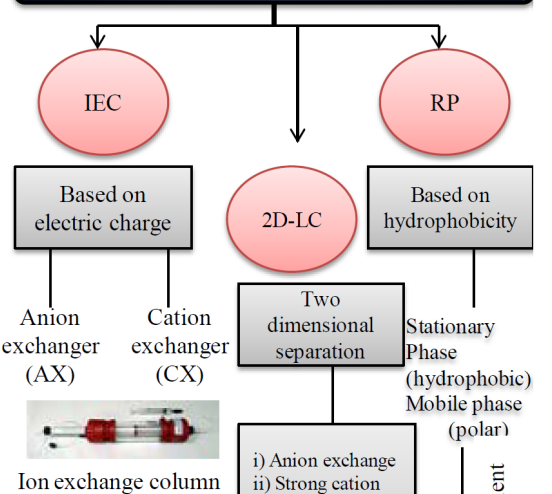

$\begin{array}{ll}\text { Ion exchange column } & \text { i) Anion exchange } \\ \text { ii) Strong cation }\end{array}$

|

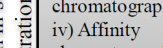

chromatography $\quad \frac{\mathrm{g}}{2}$

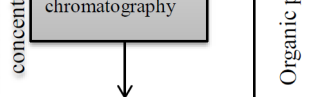

Figure 1c: Protein Separation. 


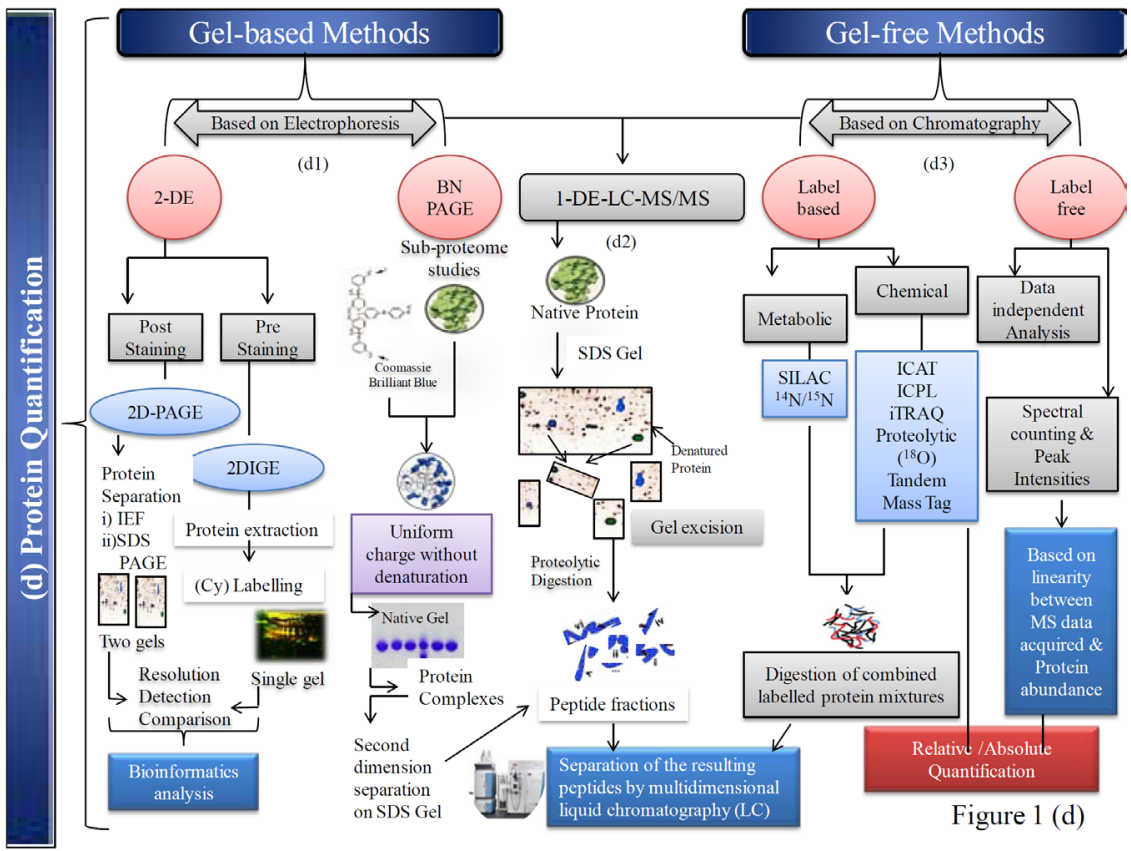

Figure 1d: Protein Quantification.

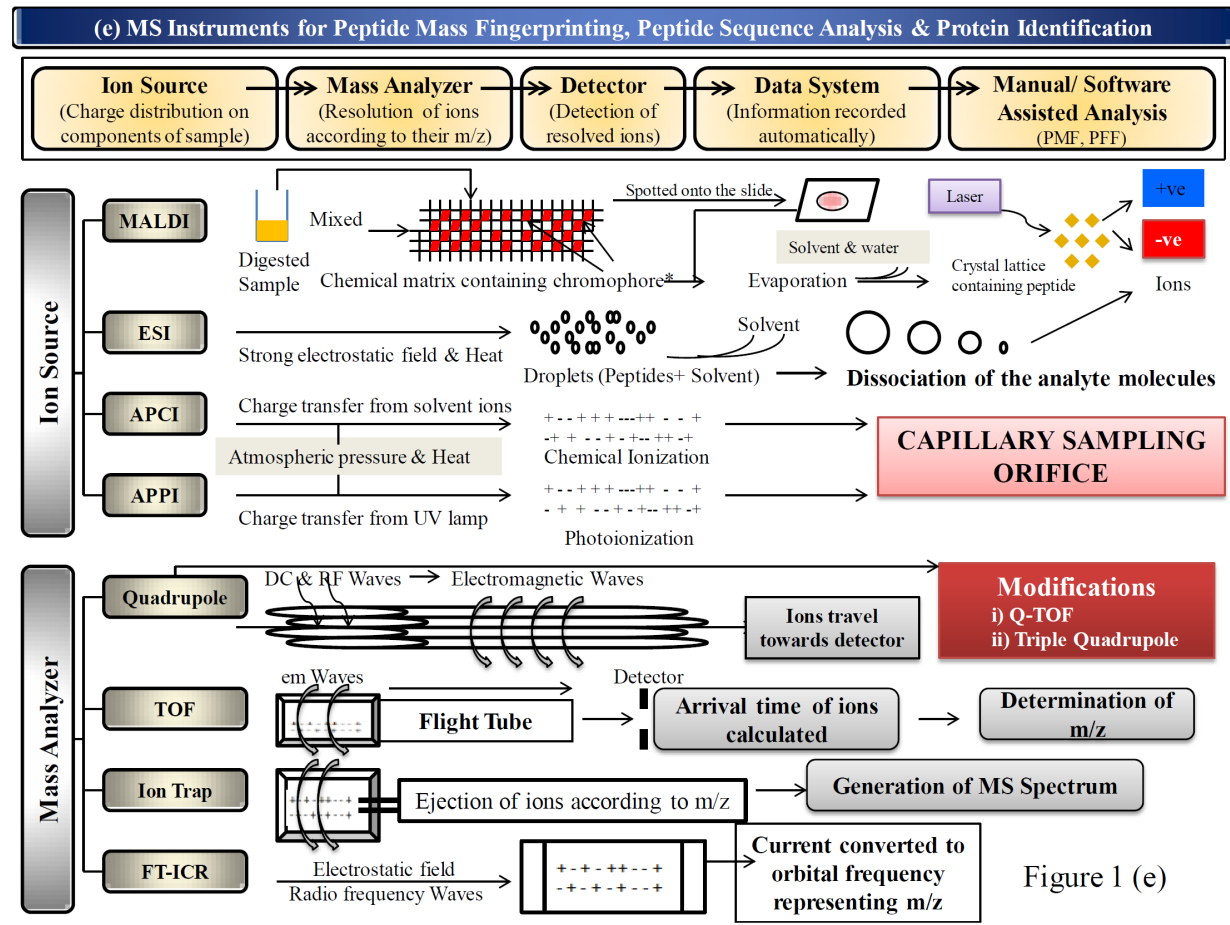

Figure 1e: Protein Identification (MS Instruments for Peptide Mass Fingerprinting, Peptide Sequence Analysis \& Protein Identification). SDS: Sodium-dodecyl Sulfate; ITP: Isotachophoresis; TE: Trailing Electrolyte; LE: Leading Electrolyte; MW: Molecular Weight; IEF: Isoelectric Focusing; pI: Iso-Electric Point; IEC: Ion Exchange Chromatography; 2D-LC: Two Dimensional Liquid Chromatography; RP: Reverse Phase; 2DE: Two Dimensional Electrophoresis; 2D-PAGE: Two Dimensional Polyacrylamide Gel Electrophoresis; 2D-DIGE: Two Dimensional Difference in Gel Electrophoresis; (Cy): Cyanine Dye; BN-PAGE: Blue Native Polyacrylamide Gel Electrophoresis; SILAC: Stable Isotope Labelling by Amino Acids in Cell Culture; ICAT: Isotope-Coded Affinity Tags; ICPL: Isotope Coded Protein Labeling; iTRAQ: Isobaric Tags for Relative and Absolute Quantification; MS: Mass Spectrometry; PMF: Peptide Mass Fingerprinting; MALDI: Matrix Assisted Laser Desorption Ionization; ESI: Electro Spray Ionization; APCI: Atmospheric Pressure Chemical Ionization, APPI: Atmospheric Pressure Photo Ionization; DC: Direct Current; RF: Radiofrequency; TOF: Time-of- Flight; Em Waves: Electromagnetic Waves; m/z: Mass to Charge Ratio; FT-ICR: Fourier Transform-Ion Cyclotron Resonance 


\section{2-Dimensional Polyacrylamide Gel Electrophoresis}

(a)
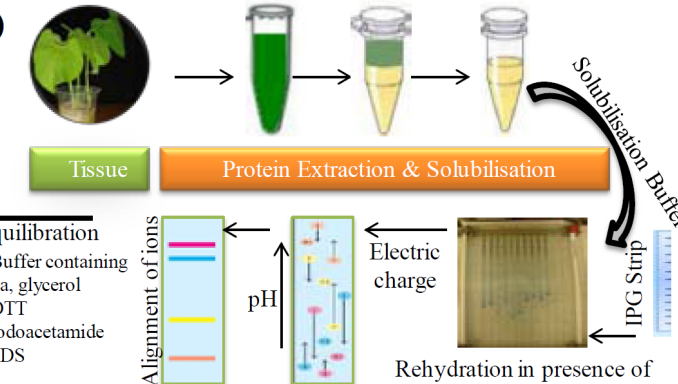

Rehydration in presence of ampholytes \& proteins

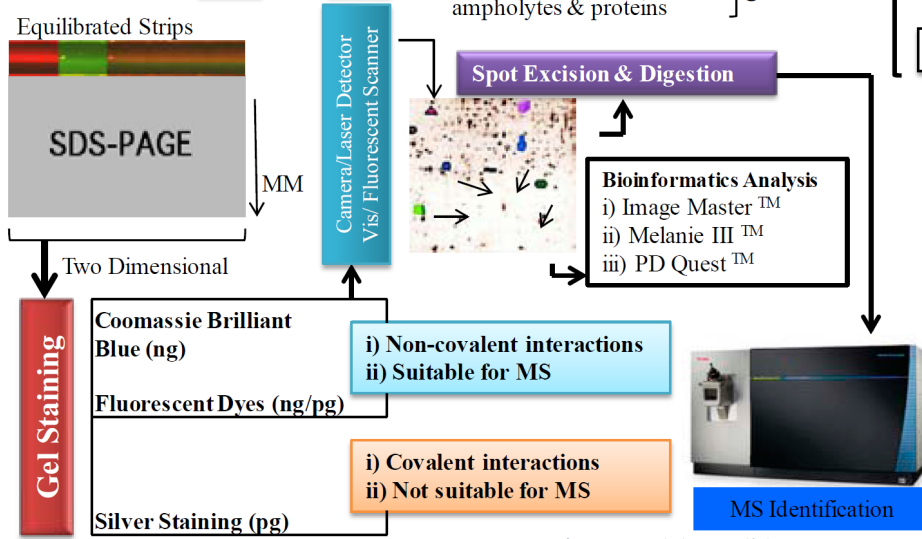

Figure2(a) \& (b)
2D-Difference in Gel Electrophoresis

(b)

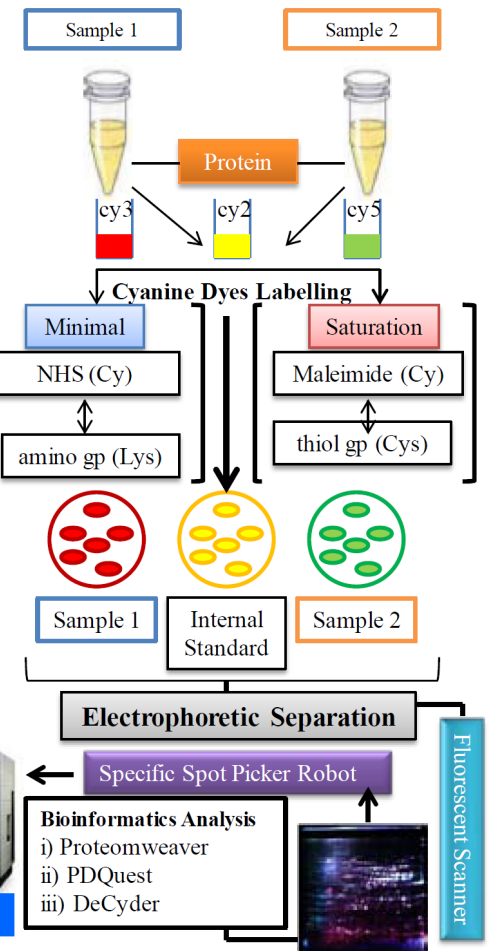

Figure 2: Schematic flowchart for technical work plan for 2DGE (Two-Dimensional Gel Electrophoresis)

(a) 2-Dimensional Polyacrylamide Gel Electrophoresis (2D-PAGE)

(b) 2D-Difference in Gel Electrophoresis (2D-DIGE)

IPG: immobilization $\mathrm{pH}$ gradient; DTT: dithiothreitol; SDS: Sodium-dodecyl sulfate;

MM: Molecular Mass; ng: Nanogram; pg: Pictogram; CY: Cyanine; NHS: N-hydroxysuccinimidyl ester; gp: Group; Lys: Lysine.

to analyse complex proteins in the sample. First of all, the sample (tissue/cell) is collected and stored under suitable conditions and used to extract proteins free from impurities. Then proteins are solubilised using ionic/non-ionic detergents and reducing agents (DTT) and finally separated. Iso-electric focusing requires IPG strips (Immobilized pH gradient strips) that contain acrylamide polymerized with bis-acrylamide and immobilins covalently bind in gel. These immobilins were used to create stable $\mathrm{pH}$ gradient [70] inside the gel. These strips are dipped in the solubilisation buffer containing extracted proteins of the sample. Both positively and negatively charged proteins (amphoteric) have specific pI (iso-electric point) at which the charge of the protein is neutralized. Different amphoteric molecules get focused on the gel corresponding to their respective $\mathrm{pI}$ when subjected under electric field. The strips are further treated with SDS and chemicals like DTT, iodoacetamide for equilibration of their chemical properties and thus leaving proteins to be analysed only on the basis of their molecular masses. The hydrocarbon tail in the SDS (sodiumdodecyl sulphate) binds to the hydrophobic amino acids through non-covalent interactions and gets distributed over entire proteins imparting negative charge all over and causes denaturation [71]. The proteins then travel from porous polyacrylamide gel (PAGE) according to their molecular weight under the influence of electric current. Different pH of buffer systems present more accurate resolution due to isotachophoresis in which proteins are aligned on the stacking gel (less $\mathrm{pH}$ ) and further separated onto resolving gel (high $\mathrm{pH}$ ) thus giving a fair start to all proteins. The buffer systems possess leading and trailing ions whose electrophoretic mobility is affected by the external $\mathrm{pH}$. Some of the most commonly used buffer systems are Tris-glycine, Bis-Tris, Tris-acetate and Tris-Tricine. Next step after resolution is the detection of the proteins which can be achieved by in-gel staining methods. The most commonly used chemicals for staining are coomassie brilliant blue, silver nitrate and fluorescent dyes that differ in terms of sensitivity, utility and suitability for MS analysis. Coomassie brilliant blue and fluorescent dyes bind noncovalently to the proteins and can be separated easily, thus suitable for MS analysis but silver staining involves covalent linking to the proteins thus not recommended for MS analysis in spite of its high sensitivity than other dyes [72]. Fluorescent dyes such as Deep Purple, SYPRO Ruby, SYPRO Red, SYPRO Orange, RuBPS, FlamingoTM, Krypton TM, ASCQ Ru, ProQdiamond, ProQemerald etc present very high sensitivity and accurate determination of protein isoforms in the sample due to their efficient compatibility with MS [73]. Stained gels are visualized using scanners/ detectors and differential spots are taken into consideration for 
further analysis (depicted in Figure 2a). The abundance of proteins is roughly assessed by the intensity of spots. However, for absolute detection, these spots are excised from the gel and subjected to enzymatic digestion producing variable peptides that undergo ionization in MS and analysed based on their different mass to charge ratios. The speed with which these peptides move towards detector is critically observed and fed to data systems. The data is then used to search matches in the databases (protein/nucleotide) for peptide mass fingerprinting using powerful automated softwares for identification of proteins [74]. This technique ensures the utilization of cost-effective technologies for adequate resolution of complex proteins and can be used along with the advanced tandem MS approaches as the first fractionation step. However, it renders errors due to greater number of steps involved and low proteome coverage due to insolubility of highly acidic or basic, hydrophobic proteins. The detection of spot intensity permits inaccuracy due to resolution of diverse proteins in the same location and thus prevents the low abundant proteins to be detected [4,75-77]. In addition to this, different experimental treatment of samples and gel-to-gel variation also contribute to the poor reproducibility of 2D-PAGE. These drawbacks are overcome by 2D-DIGE technique that allows resolution on single gel rather than separate gels.

2D-DIGE (Two Dimensional Differential Gel Electrophoresis) This modified gel based technique offers few advantages over 2D-PAGE by minimizing the errors caused by gel-to-gel variation and need for analysis of more than one gel thereby reducing manual error. The protein samples are pre-stained by using cyanine-based fluorescent dyes. The NHS (N-hydroxysuccinimidyl) ester group and maleimide derivatives of these dyes react with the amino and thiol groups of the protein respectively. The labelling is performed in two ways- minimal labelling and saturation labelling [78]. Former deals with the labelling of N'terminal of lysine residues by amide linkage to NHS ester group (required for maintaining the multiple charges on the surface of protein thereby preventing in solubilisation) and later facilitates the binding of thiol groups of cysteine residues to the maleimide derivatives of dyes (recommended for low abundant proteins due to high sensitivity) leading to comparatively wide proteome coverage. The cyanine based dyes should be tagged such that they might not influence the mobility of proteins when subjected to electrophoresis [79]. The labelling of different samples with resolvable fluorescent cyanine based dyes allows differential expression studies. The protein samples to be quantified are labelled with Cy3 and Cy5 dyes that impart different colours when visualized by fluorescence scanner and thus depict the amount of protein within the sample by measurement of spot intensity (Illustrated in Figure $2 \mathrm{~b}$ ). These labelled proteins along with the internal standard Cy2 (representing presence of both the samples) is used for normalization of the ratios of intensities retrieved from different samples paving way for accurate quantification of proteins. The labelled protein samples are mixed and subjected to electrophoretic separation in a single gel thereby eliminating the need to analyse more gels and reducing the experimental error. The stained images are captured, scanned, digitalized and the fluorescence intensities of variable samples are analysed and the data is fed to efficient softwares such as DeCyder, Proteom weaver PDQuest and Progenesis [70] for comparison of spot intensities and useful information is generated depicting to the abundance of specific proteins. DIGE technique is more appealing as compared to 2D-PAGE in terms of sensitivity, reproducibility, reliability, accuracy, automation, and more suitability for more diverse proteins \& MS analysis. The gel based techniques have been applied for differential protein expression studies in plants [17,80-84]. And few research findings emphasized the equivalent need of gel based techniques to accomplish the task of protein annotation [85-88]. Regardless of so many advantages of 2D-DIGE, it is unable to beat some of the immanent drawbacks of gel based approaches like narrow-coverage of proteins due to tagging of lysine and cysteine amino acids only, insolubility of some of the membrane proteins and sample preparation variation.

Advancements in the field of proteomics have led to the emergence of gel-free proteomics approach that addresses the issues such as reproducibility, low-proteome coverage, quality of data obtained that are observed in case of gel-based methods. Gelfree methods are mainly dependent on LC-MS/MS technique and instead of examining one spot at a time, it takes into consideration all the peptides generating from the proteins proving to be more robust and extremely informative high-throughput strategy.

\section{Gel free methods}

Gel free methods can be considered as a direct consequence of the numerous innovative developments in the past two decades. These methods eliminate few of the major experimental errors observed in case of gel based approaches. Gel free approaches can be mainly classified into two categories i.e., label-based approaches and label free approaches [89]. These methods utilize the proficient liquid chromatography and mass spectrometry tools to generate the quantification data thereby promising efficient protein studies. The gel free strategy is quite simple and engages few steps in which proteins are isolated, digested (labelled/non-labelled), eluted on liquid chromatography and detected to be analyzed by mass spectrometry approaches for absolute or relative quantification. Wide methodologies pertaining to label-based and label-free approaches are discussed in the following sections.

\section{Label based methods}

Label-based approaches utilize specialized isotope/isobar tags having specific groups that label proteins and peptides chemically/metabolically or enzymatically [90]. The steps undertaken for label-based quantification are depicted in Figure 3 a \& b. The separation of these labelled peptides on LC and further analyses by highly sensitive MS technique yields highly informative data for retrieving precise results by comparing the relative abundances of heavy and light samples. Numerous experiments have been conducted using label based strategies to understand the mechanisms of various developmental stages, stress physiology by differential expression studies [26,28,9195]. The label based approaches assure automated highthroughput quantitative proteome analysis of unknown proteins with reliable automated and multiplexing abilities. Proteins/ 

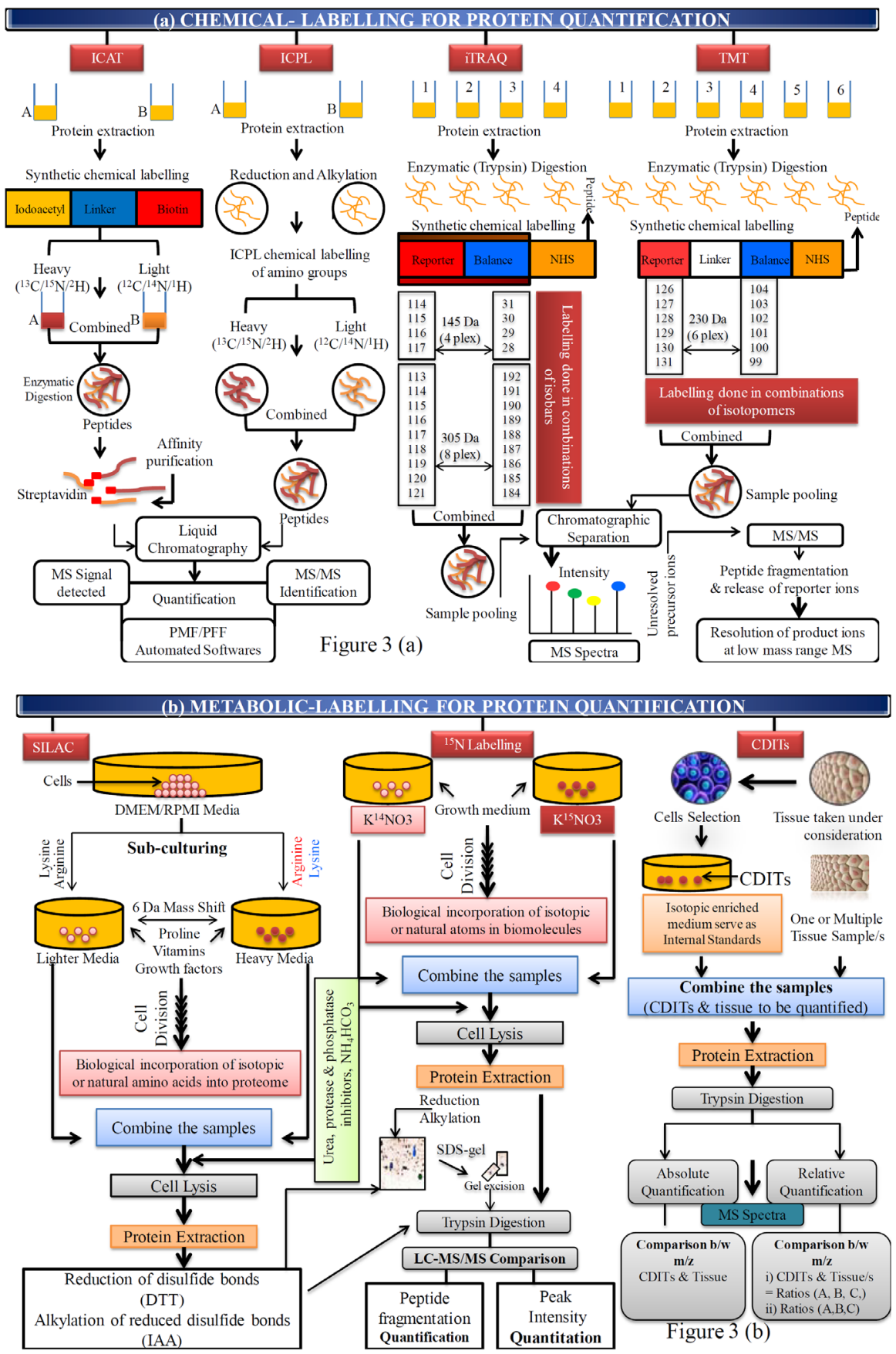

Figure 3: Outline of technical work plan for label-based proteomics

(a) Chemical Labelling for Protein Quantification

(b) Metabolic Labelling for Protein Quantification

ICAT: Isotope-Coded Affinity Tags; tag consists of three functional elements i.e. iodoacetyl group (yellow) binds to thiol-specific groups, linker (blue) introduces mass shifts and biotin (red) used for reducing complexity by affinity purification.

ICPL: Isotope Coded Protein Labelling; modified version of ICAT that permits multiplexing and labelling of almost all peptides.

iTRAQ: Isobaric Tags for Relative and Absolute Quantification; tag consists of reporter (red) that introduces mass differences, balance group (blue) that maintains the similar weight of all reporter group in tags and NHS group (yellow) that binds specifically to peptides.

TMT: Tandem Mass Tag; differs from iTRAQ with respect to the presence of additional linker group (white) and isobars used.

SILAC: Stable Isotope Labelling by Amino Acids in Cell Culture; DMEM: Dulbecco's Modified Eagle Medium, RPMI Medium: Roswell Park Memorial Institute Medium, DTT: dithiothrietol, IAA: indole acetic acid

15N Labelling: Differs from SILAC in terms of incorporation of labelled elements through inorganic chemicals instead of labelled amino acids. CDITs: Culture-Derived Isotope Tags; can be used for absolute quantification as well. 
peptides are labelled either chemically (using isotopes or isobars) or metabolically to introduce mass shifts for distinguishing the relative intensities of the proteins in the samples.

Chemical labelling: The method involves utilization of chemically synthesized tags that incorporate variable isotopes and isobars which introduce mass difference within the labelled proteins (ICAT) and peptides (ICPL, iTRAQ, TMT) for their differential expression studies based on the abundance of peptides detected by their peak intensities (based on $\mathrm{m} / \mathrm{z}$ ) and MS/MS fragmentation. This strategy offers accuracy and simultaneous comparison of more than two samples. It has been further sub-divided into isotopic (ICAT \& ICPL) and isobaric (iTRAQ \& TMT) labelling

Isotope-Coded Affinity Tags (ICAT): The first in vitro method that permits tagging of proteins and peptides of all types of biological samples using stable isotopes was developed by Gygi and his associates in 1999 [96]. This technique employs ICAT reagents that consist of mainly iodo-acetamide group or N-ethymaleimide, a spacer or linker arm and biotin. Iodoacetamide group/N-ethymaleimide is highly specific chemical reactive group that alkylates thiol group of cysteine residues in the protein sample. A spacer or linker arm is meant for introduction of mass shift by incorporation of different isotopes in different samples. Isotopes used for this purpose are proton $(\mathrm{H}) /$ deuterium (D), ${ }^{12} \mathrm{C} /{ }^{13} \mathrm{C},{ }^{15} \mathrm{~N} /{ }^{16} \mathrm{~N}$ that introduce mass difference of upto 8Da due to presence of these elements in the labelled or unlabelled amino acid residues producing light and heavy tags. Biotin group assists purification of labelled peptides by affinity chromatography in biotin-avidin/streptavidin systems and thus captures all the cysteine containing peptides from the mixture. The strategy employs isolation of protein from two samples followed by synthetic chemical labelling using ICAT reagents; one with heavy and other with light isotopes. The labelled samples are then pooled, enzymatically digested to peptides and subjected to affinity purification by biotin moiety to reduce sample complexity. The next step involves the removal of biotin as it decreases the resolution efficiency of mass spectrometry [96] using acid-cleavable (ALICE/ introduction of disulphide bond in linker) or photo-cleavable linkers (UV light) $[97,98]$. The peptides are then allowed to resolve on liquid chromatographic separations and further analysed by tandem mass spectrometric techniques. Relative peak intensities obtained in MS spectra directly correlates to the abundance of respective peptides in the sample whereas tandem MS allows peptide mass fingerprinting by detection of product ions generated during peptide fragmentation which leads to identification of proteins. The technique offers accuracy as samples are similarly treated by protease preventing experimental variations and reduced sample complexity due to tagging of only cysteine residues but is also associated with loss of information leading to lower proteome coverage. To overcome these limitations, other tags have been developed that allow multiplexing as well.

Isotope-Coded Protein Labelling (ICPL): The ICPL strategy, referred to as modified version of ICAT approach was developed by Schmidt and co-workers that solved major shortcomings of confined sequence coverage and low throughput [99]. It utilizes amine-reactive $N$-nicotinoyloxy-succinimide tags that cause derivatization of free amino-terminal groups and $\varepsilon$-amino groups of lysine residues and introduce mass difference of $4 \mathrm{Da}$ and $\sim 6$ Da in case of $\mathrm{H} / \mathrm{D}$ and ${ }^{12} \mathrm{C}_{6} /{ }^{13} \mathrm{C}_{6}$ labelling respectively. The first step involves extraction, reduction and alkylation of protein samples to ensure uniform labelling of all free amino terminals of lysine residues. The heavy and light labelled protein samples are then pooled and subjected to enzymatic digestion. Since lysine residues are labelled, treatment with trypsin will generate longer fragments, thus Glu-C endoproteinases in addition to trypsin are used for digestion to obtain shorter fragments. ICPL tags are hydrophilic in nature and help to maintain the intrinsic characteristics of peptides that allow efficient quantification. The isotopes used in ICPL tags can be used in varied combinations for multiplexing (triplex and quadruplex) and differentiates the sample by even $2 \mathrm{Da}$. This method permits labelling of lysine containing peptides that are found abundant as compared to cysteine residues in most of the proteins and eliminates the confined sequence coverage of proteome to some extent but not completely as lysine is also absent in some of the proteins. To overcome this issue, post-digest ICPL approach was developed that allows labelling of peptides after enzymatic digestion. All the free $\mathrm{N}$-terminals of peptides are labelled uniformly and thus the results obtained are non-biased and considered to be more accurate [100]. The digested labelled peptides are separated on liquid chromatography and finally analysed on MS for quantification and identification of proteins. ICPL strategy is observed to be very suitable for efficient MS/MS fragmentation and detection of peak intensities and also offers the analysis of post-translational modifications and isoforms [101]. Despite of advantages over ICAT method, post digest ICPL involves labelling after digestion which can lead to manual error and the tags can interfere in the mobility of peptides when subjected to liquid chromatography [102]. In addition to isotopes, isobars have been employed for the quantification purpose that can introduce mass difference of even 1 Da and efficient multiplexing (iTRAQ \& TMT).

Isobaric Tags for Relative and Absolute Quantification (iTRAQ): ITRAQ strategy has been utilized efficiently to explore the diverse molecular mechanisms occurring in plants. The strategy involves isobaric labelling of peptides; introduced by Ross and his associates in 2004 [103]. The isobaric tags bind covalently to the $\mathrm{N}$-terminal of peptides; introduce a mass shift of even 1Da and thus paves way for multiplexing. The tag is comprised of three main functional elements i) Reporter group that introduces mass shifts ii) Balance group that is required to maintain the overall mass of isobaric tag iii) NHS group which specifically binds to the peptide. Chemically, reporter group is N-methylpiperizine which provides a mass shift range; balance group is mainly carbonyl group whose mass is adjusted according to the reporter group so that all tags have same mass for combined reporter and balance group and NHS ester group is amine reactive. The isobars are employed in varied combinations leading to efficient comparison of two, four and eight samples simultaneously which is otherwise not possible in case of ICAT strategy. Reporter groups have a mass range varying from 114- 
$117 \mathrm{Da}$ and 113-121 Da that are compensated by balance group having a range from 28-31 Da and 184-192 Da in 4-plex (mass tag $=145 \mathrm{Da}$ ) and 8-plex (mass tag $=305 \mathrm{Da}$ ) respectively. Thus, the overall mass of reporter and balance group remains constant (as shown in Figure 3 a). The strategy includes labelling of enzymatically digested protein samples in which NHS-group binds covalently to all the $N$-termini of peptides equally. The labelled peptides are then further analysed by LC-MS/MS. All the labelled peptides are resolved by chromatographic separation and detected by MS to generate spectra. However, the peptides remain unresolved as second round fragmentation of peptides is necessary for producing product ions associated with release of reporter ions. For this purpose high quality MS with triple quadrupole is used. The ions entering are fragmented by less collision energies to produce precursor ions which cannot be distinguished and presented as a single peak. These precursor ions are again introduced under the influence of high collision energies to give product ions that are detected and resolved to generate spectra for simultaneous protein quantification and identification when retrieved information is searched against available protein and nucleotide databases. Although iTRAQ strategy has been utilized extensively in the past years due to its high accuracy and multiplexing abilities, it is associated with the need of high-throughput data acquisition system and modified versions of MS that can read slight mass differences.

Tandem mass tag: This technique shares the same principle as iTRAQ strategy with slight variation in the chemical structure of the tag used for labelling. ${ }^{13} \mathrm{C} /{ }^{15} \mathrm{~N}$ isotopomers are mainly used in varying proportion to create mass difference. The tag is comprised of reporter region (creates mass difference), linker region (conjugates reporter to balance group and is easily cleavable), balance group (maintains constant mass) and protein reactive group (binds to amine/cysteine/carbonyl) [104]. The reporter group mass varies from 126-131 Da which is maintained to a constant mass of 230 Da by balance group having mass ranging from 99-104 Da which leads to 6-plex analysis. Similar to ITRAQ, this technique involves efficient uniform labelling of peptides (amine-) and cysteine residues (cys TMT) after enzymatic digestion of proteins. The reporter ions are released at the time of peptide fragmentation in MS/MS, produce spectra that is recorded and finally the abundance of peptides is interpreted that allows protein identification and relative quantification.

Although chemical labelling presents accuracy in determination of peptide abundance and overcomes in-gel experimental variation, it requires careful sample preparation methods and highly efficient mass spectrometric analysis which can discriminate peptides varying by even 1 Da mass. Multiplex versions are undoubtedly presenting proficient comparison but are associated with complicated data analysis due to its inability to select peptides after one round of fragmentation. The major drawback of these techniques is that pooling of samples is done just before LC-MS/MS analysis which creates space for experimental biasness and inaccuracy. To overcome the limitations of in vitro techniques, metabolic labelling came in limelight that incorporates the tags in the samples from the very beginning.
Enzymatic labelling: This method employs substitution of natural $\left({ }^{16} \mathrm{O}\right)$ and isotopic oxygen $\left({ }^{18} \mathrm{O}\right)$ in the carboxyl groups of amino acid residues. The isolated proteins are digested by proteases that target serine, lysine and arginine residues in presence of heavy water $\left(\mathrm{H}_{2}{ }^{18} \mathrm{O}\right)$ and light water $\left(\mathrm{H}_{2}{ }^{16} \mathrm{O}\right)$. Later, Hcl was used to serve as catalyst for labelling of carboxyl terminal residues along with water $\left(\mathrm{H}_{2}{ }^{18} \mathrm{O} / \mathrm{H}_{2}{ }^{16} \mathrm{O}\right)$ referred to as acid mediated oxygen substitution [105]. During the enzymatic digestion, amide bond is broken and one isotopic oxygen atom is substituted in carboxyl group. The cleaved peptide undergoes one more substitution in place of second oxygen of carboxyl group in presence of enzyme creating three possibilities for mass differences i.e., ${ }^{16} \mathrm{O} /{ }^{16} \mathrm{O}(\mathrm{ODa}),{ }^{16} \mathrm{O} /{ }^{18} \mathrm{O}(2 \mathrm{Da}),{ }^{18} \mathrm{O} /{ }^{18} \mathrm{O}(4 \mathrm{Da})$ when compared to unlabelled peptides. The mass differences are detected to depict the relative abundance of peptides by comparing their ionic intensities. This method allows efficient incorporation of tags but permits side reactions that interferes with accurate data analysis. However, to inhibit undesirable reactions, suitable buffers and esterification is performed methanol and deuterated methanol [106].

Metabolic labelling: Metabolic labelling strategy employs biological incorporation of isotopic amino acids and elements through cell culture in plants and dietary food in animals. It surpasses the major drawback of in vitro labelling and eliminates experimental error to a great extent. After the intake of labelled amino acids inside the body, the cells are rapidly multiplied and undergo vast array of cellular processes that ensures efficient incorporation of isotopes. Metabolic labelling can be carried out by either isotopic essential amino acids (arginine, lysine, leucine, and tyrosine) or isotopic elements $\left({ }^{13} \mathrm{C},{ }^{15} \mathrm{~N},{ }^{2} \mathrm{H},{ }^{18} \mathrm{O}\right)$. Despite of so many advantages, it lacks applicability for all biological samples and is somewhat tedious and expensive.

Stable Isotopic Labelling of Amino Acids in Cell Culture (SILAC): SILAC is a simple in vivo technique that was first developed in 2002 [107]. Later on, the method was efficiently introduced in eukaryotic organisms as well. Isotopic lysine $\left(\mathrm{C}_{6} \mathrm{H}_{14} \mathrm{~N}_{2} \mathrm{O}_{2}\right)$ and arginine $\left(\mathrm{C}_{6} \mathrm{H}_{14} \mathrm{~N}_{4} \mathrm{O}_{2}\right)$ amino acid tags are mainly used in this strategy. Looking at the chemical structure, it can be estimated that isotopic and normal amino acid will have a mass difference of $6 \mathrm{Da}\left({ }^{12} \mathrm{C} /{ }^{13} \mathrm{C}\right), 2$ Da $\left({ }^{14} \mathrm{~N} /{ }^{15} \mathrm{~N}\right)$ and likewise varied combinations of isotopic amino acids will lead to simultaneous high-throughput analysis of more samples. First of all, a cell culture medium is prepared and cells whose proteome is to be analysed are grown. The medium is divided into two sections, one is provided with labelled amino acids and other with unlabelled amino acids (as shown in Figure 3b). The cells are allowed to divide for four to five generations after subculturing in presence of similar growth regulators and conditions to confirm the unbiased incorporation of amino acid residues. To validate the efficient labelling of cells with heavy isotopes, mass spectrometric analysis is performed. The cells from both the culture medium are then pooled and proteins are extracted, treated with reducing agents and alkylated using iodoacetamide. The reduced proteins are then treated with trypsin for digestion to peptides. This can also be performed after separation of reduced 
proteins on SDS-PAGE. The mixture of peptides is co-eluted in liquid chromatography (reverse phase or strong ion exchange chromatography). The separated fractions are then further analysed by mass spectrometric techniques. This technique ensures less chance of biasness and handling errors with $100 \%$ incorporation of tags if grown for sufficient time [108]. SILAC strategy can provide absolute quantification of proteins provided there is no undesirable metabolic conversion of labelled amino acids to other by products (eg arginine is converted to proline). Except the labelled amino acids, all other amino acids present in sample should be non-isotopic and present in sufficient amount to eliminate the probability of side reactions. The technique has been modified to identify post-translational modifications, especially methylation by using heavy-methyl SILAC approach [109]. The technique has certain limitations associated to suitability of biological material in question and laborious steps involving highly proficient tools and expensive synthesises of tags.

${ }^{15} \mathbf{N}$ labelling: The first metabolic labelling study was performed using isotopically enriched media containing ${ }^{15} \mathrm{~N}$ and is observed to be appropriate mainly for prokaryotes. The technique utilizes same strategy as SILAC with the difference of incorporating isotopic elements instead of amino acids. The labelled and unlabelled elemental nitrogen is provided to the growing cells by introducing inorganic salts in the culture medium (as shown in figure $3 \mathrm{~b}$ ). The cells are grown separately in the medium containing all the essential components required for growth. One sample is provided with the isotopic labelled element (heavy ${ }^{15} \mathrm{~N}$ ) and other is grown in presence of natural Nitrogen element (light ${ }^{14} \mathrm{~N}$ ). Multiple division of cells is allowed for few generations and then samples are mixed, protein is extracted, reduced, alkylated and digested by trypsin. The labelled and unlabelled peptides are then eluted on chromatographic separation and finally analysed by MS to generate ion chromatograms depicting intensities that are directly proportional to their relative abundances. The technique facilitates incorporation of $\sim 98 \%$ tags but lacks in precision due to variation in number of nitrogen in peptides and also peptide sequences. Thus it makes the analysis and interpretation complicated.

Culture-Derived Isotope Tags (CDITs): This technique provides absolute and relative quantification of proteomes by using labelled internal standards. This strategy has been derived from SILAC technique as it is also associated with in vivo introduction of isotopes in cultured cell [110]. The cells are chosen from the tissue (taken under consideration for protein quantification). These cells are grown in suitable culture medium in presence of isotopes, thus referred to as culture-derived isotope tags (CDITs). The CDITs are mixed with the tissue sample which is to be analysed. The strategy further allows combined extraction of proteins followed by reduction and digestion to peptides. Now, the peptides from labelled (CDITs) and unlabelled (tissue sample) are analysed by mass spectrometry. Ion chromatograms are generated that depict $\mathrm{m} / \mathrm{z}$ ratio of labelled and unlabelled peptides, isotopic distribution of peptides is observed and thus the quantity of the peptide in question is estimated. The calculated ratio of sample $(\mathrm{m} / \mathrm{z}$ of same sequence of labelled peptides serving as reference and unlabelled peptides of tissue) depicts the absolute abundance of respective peptide. In case of more than one sample, same CDITs are added to all the different samples serving as internal standard. Protein from different samples $\left(\mathrm{T}_{1} / \mathrm{T}_{2} / \mathrm{T}_{3} / \mathrm{T}_{4}+\right.$ CDITs $)$ is extracted and digested separately. Mass to charge ratio for all the samples having internal standards are calculated which shows isotopic distribution between CDITs and tissue sample. The number of ratios calculated is equal to the number of samples addressed and these calculated ratios are finally compared to estimate the relative abundance of peptides (as depicted in Figure 3b).

To date, a lot of experiments have been conducted and published for biological studies in plants using label-based approaches due to wide applicability and accuracy. However, this method involves many steps and the samples that can be analysed are limited. Moreover, handling errors could lead to incomplete incorporation of tags and give way to side reactions. These constraints have been taken away by more advanced labelfree approaches that allow direct analysis on LC and comparison on the basis of mass spectrometric data.

\section{Label Free Methods}

Label-free approaches evolving rapidly are considered to the most robust and accurate technique that provides higher dynamic range of quantification. In this strategy, the isolated protein are enzymatically digested and subjected to high resolution chromatographic separation. The eluted peptides are then transferred to MS where $\mathrm{m} / \mathrm{z}$ ratios are analyzed and chromatogram depicting signal intensities are retrieved. It has been validated that the signal intensities of peptides provide a direct measure for its abundance in the sample [111,112]. The peptides are further fragmented by triple quadrupole mass analyzer where high and low collision energies are responsible to collect information for precursor and product ions; referred to as Tandem MS (MS/MS). MS/MS data provides correct information regarding the identity of proteins by comparing peptide masses obtained from analysis to that in the nucleotide/protein databases through powerful dedicated softwares. This reveals the identity of unknown proteins as well. The first software to be used for peptide matching was Sequest introduced in 1994 [113]. The most important advantage of label-free approaches is that we can compare as many protein samples as possible by comparing the signal peak intensities and MS spectra after individual separation and detection of all samples on LC-MS/ MS. (Figure 4 a \& b) demonstrates various global and targeted approaches for relative/absolute quantification of proteins.

\section{Relative quantification}

This approach is based on data dependent MS and MS/MS based label-free analysis. MS data is retrieved mainly in the form of MS spectra and signal intensities. These criteria's are assessed to interpret the identification and relative abundance of peptides in the sample. This approach has been broadly categorized in to two methods i.e., spectral intensities measurements and spectral 


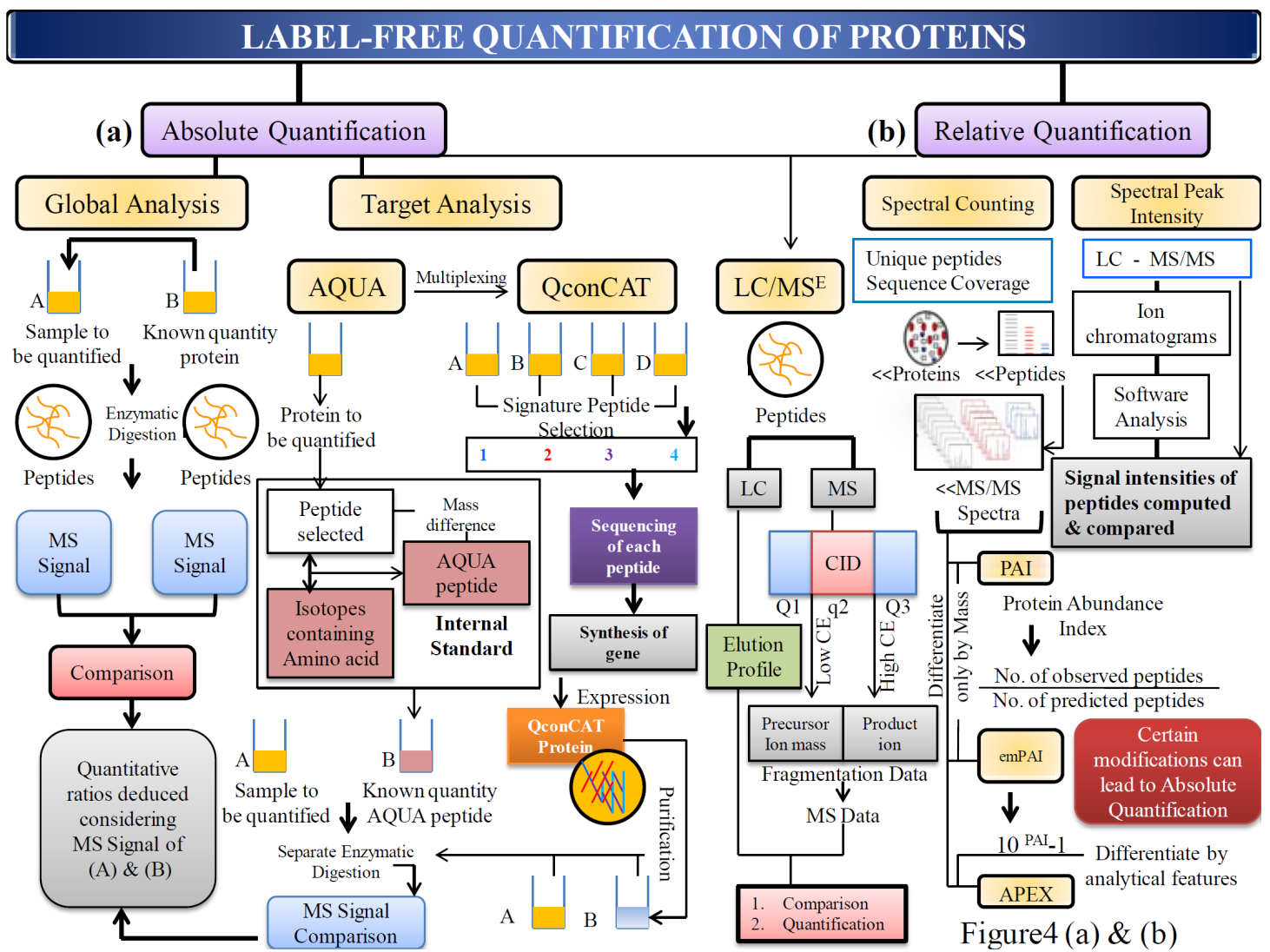

Figure 4: Major approaches and steps involved in label-free proteomics

(a) Absolute Quantification

(b) Relative Quantification

AQUA: Absolute Quantification of Proteins; QconCAT: Quantification by Concatenated Signature Peptides Coded Affinity Tags; LC/MSE : Liquid Chromatography Mass Spectrometry and E (superscripted) Stands for Elevated Energy; CID: Collision Induced Dissociation; Q1, q2, Q3 stands for Quadrupoles 1, 2 \& 3 respectively, Low CE: Low Collision Energy; High CE: High Collision Energy; emPAI: Exponentially Modified Protein Abundance Index; APEX: Absolute Protein Expression; LC-MS/MS: Liquid Chromatography Tandem Mass Spectrometry.

counting [114]. Certain modifications in these techniques can lead to absolute measurement of protein (APEX).

\section{Spectral intensities measurements}

This technique employs the detection of ion intensities to estimate the quantity of protein in the sample. The first step involves preparation of sample in which the protein to be analysed is isolated individually from the source and subjected to high resolution liquid chromatographic separation; ultra-HPLC is the method of choice for this purpose. All the peptides under consideration are eluted by presenting a specific $\mathrm{m} / \mathrm{z}$ ratio and specific retention time $[115,116]$. Using dedicated software's, ion chromatograms are generated that are automatically aligned. Now, the same peptide present in the samples to be quantified possess a particular $\mathrm{m} / \mathrm{z}$ ratio and retention time. On the basis of these observed properties, peptide matching is performed either to that with other sample or reference in databases. When analysed on MS, peptides face collision energy under the influence of voltages inside the quadrupole and produce precursor ions. The total ion current of signal is computed and calculated for each peptide. On the basis of $\mathrm{m} / \mathrm{z}$ ratio, retention time (elution profile) and signal intensities, area under curve (AUC) is calculated using automated software's. AUC is directly proportional to the quantity of peptide and used to compare the abundance of peptides in different samples. In short, the strategy involves identification of peptides on the basis of $\mathrm{m} / \mathrm{z}$ ratio and retention time when compared to reference and quantification of identified peptides by computing area under curve depicting signal intensity. For accurate measurements, one should be aware of basic elution profile characteristics of the peptide; this leads to bypass of some of the low abundant or unrecognized peptides. Calculation of number of spectra provides more dynamic range in this regard.

\section{Spectral counting}

Spectral counting can be regarded as a quantitative approach based on the rationale that the number of MS/MS spectra of peptides is directly proportional to the quantity of protein from which they are obtained. Recent study has reported the correlation of spectral count to that of fold change observed 
and that the number of spectra is correlated to the peptide count [117]. This strategy is mainly based on MS/MS analysis for simultaneous identification and quantification of proteins in contrast to peak intensity measurements that relies on MS analysis. In this approach, sample preparation and digestion steps are undertaken to produce tryptic peptides. These peptides are subjected on liquid chromatography and further analysis is performed by tandem mass spectrometry. The peptides are eluted independent of their physical characteristics but the analysis yields different retention time and chromatographic peaks data which distinguishes the spectral count of each peptide without the need to align chromatograms. The more the quantity of proteins, the higher will be the number of MS/MS spectra of the related peptides. Again, large proteins produce greater number of tryptic peptides and thus more spectral count. The spectral or peptide count from the samples to be analysed are compared and relative abundance of proteins are determined. Certain methods have been introduced to measure the peptide count i.e., i) protein abundance index [118], ii) exponentially modified protein abundance index [110]. And iii) absolute protein expression [119]. Protein Abundance Index (PAI) is calculated by computing the ratio of the number of peptides observed in the sample within the given specific range of MS to the expected peptides that can be observed after trypsin digestion of analysed protein. This method has been modified by its normalization which distinguishes the sequence on the basis of their characteristics presenting a better correlation for assessment of protein quantity. The method is referred to as the exponential form of PAI represented as emPAI (exponentially modified protein abundance index) and represented as $10^{\mathrm{PAI}}-1$ [70]. This is based on the concept that larger proteins have more peptides and thus show a direct correlation to the protein content in the sample. The major drawback of these methods is the neglected intrinsic characteristics of proteins that are surpassed by certain advancements. Another modified version of emPAI is Absolute Protein Expression (APEX) which takes into consideration the physicochemical properties of proteins and analytical features of MS analysis. In this strategy, computational models are used to predict the possibility of tryptic peptides that can be produced within the given dynamic range of MS. This estimate of peptides is then compared to the observed peptides that are actually detected. It deduces a correct order of magnitude to depict the influence of intrinsic features of protein. From the estimate, a correction factor for each molecule of a particular protein is included in the analysis, called as $\mathrm{O}_{\mathrm{i}}$ value [120]. In this way, the likelihood of the occurrence of a peptide of particular protein is estimated and gives absolute protein concentration per cell.

\section{Absolute quantification}

This strategy is the direct consequence of various modifications and rapid growth in the field of proteomics. The techniques offer accurate measurements of proteins present in the sample by taking into account the reference or internal standards. In this regard, we can classify the methods in two major categories i.e., Global Analysis and Target Analysis.

Global Analysis: In the former approach, a known quantity of protein is added to the sample which is to be quantified. Separate enzymatic digestion is done for known protein and its MS signal intensity is observed and recorded. Then the sample to be analyzed (containing known amount of protein) is separately digested and analysed on MS. The mass spectrometric data obtained for both the known protein and the sample is then compared. The same peptides of reference and test sample produce similar elution profile. The ratio of the signal intensity is thus used to deduce the absolute abundance of the peptides in the sample.

Target Analysis: As described in the former approach, all the peptides of the corresponding protein are considered for analysis. But in target approach, only a few selective peptides are quantified by utilizing isotopic labelling strategy. The most previous approach employed for targeted protein analysis was ELISA but it requires specific antibodies and complete information of the proteins to be analyzed and thus not suitable for analysis of noval proteins. Recently, AQUA strategy has been introduced that employs standard peptide for absolute measurement of particular peptides present in the protein. For reference, targeted peptide which is to be analysed is selected from the protein and labelled using isotopes containing amino acids. This labelled peptide is also referred to as AQUA peptide. The reference peptide is added to the protein sample from which peptide abundance is to be measured. The sample is enzymatically digested and analysed on mass spectrometric tools. The signal intensities appear as duplets for a specific peptide as there is slight mass difference between the AQUA peptide (isotopically labelled) and natural peptide present in sample. The relative intensities of both the peptides are observed and recorded. The calculation of ratio of AQUA peptide to that of sample peptide depicts the absolute quantification of protein.

Another strategy that has been derived from AQUA for simultaneous analysis of more than one sample is QconCAT technique. This multiplex strategy involves the selection of unique peptide from each sample of protein to be analysed. These peptides are then sequenced and a chimeric gene is synthesized using computational tools [73]. The expression of chimeric gene leads to the production of protein representing signature peptide of each protein and is referred to as concatenated protein (QconCAT). The isotopic labelling of QconCAT protein serves as internal standard [121]. It is mixed with different samples of protein to be quantified. Again, enzymatic digestion and analysis on MS tools produces signals that are recorded and used to compare and derive ratios for measurement of absolute peptide abundance.

$\mathrm{LC} / \mathrm{MS}^{\mathrm{E}}$ approach is based on data independent acquisition and is amenable for absolute and relative quantification. In this technique, the digested peptides are eluted on high resolution chromatographic system and subjected to advanced high mass resolution MS that utilizes triple quadrupole/TOF. The instrument is provided with electromagnetic waves and alternating high and low collision energies. As the product enters the system, gets fragmented in presence of low collision energies to generate precursor ions. However, selection is not 
done at this level for further splitting and thus termed as data independent analysis. The precursor ions are again fragmented in presence of high collision energies generated by inert gases to yield product ions. The record of retention time, $\mathrm{m} / \mathrm{z}$ ratio and signal intensities assist in the grouping of generated ions to their respective source. Product ions and precursor ions have similar elution profile and generate signatures, called as Exact Mass Retention Time (EMRT) signatures [122]. The intensity of these ions when analysed on MS, generates particular EMRT signatures for specific peptides and thus can be correlated to the abundance of their corresponding peptides.

Label-free approaches are considered to be the most advanced innovative emerging techniques that attempt to generate highly informative data for identification of novel proteins. The multiplexing technology eliminates the need for laborious sample processes, isotopic labelling and the number of steps involved but requires highly efficient and advanced versions of proteomic tools thereby leading to cost issues. However, it has contributed excessively in the recent years towards identification of proteins and understanding of biological mechanisms.

All the proteomic strategies are complementary to each other associated with several advantages and drawbacks. The integration of all these techniques will be useful to get a clear picture of wide mechanisms taking place in living systems. In this regard, few of the recently published works on plant proteomics have been depicted in Table 1. Incremental improvements in these strategies will lead to uncover orphan genes and gain indepth knowledge of protein dynamics.

\section{Summary}

Table 1: Recent key studies for identification of novel proteins and differential expression studies in plants under specific conditions using proteomic approaches.

\begin{tabular}{|c|c|c|c|c|}
\hline S.No. & Plant & Technique & Biological Study & Reference \\
\hline 1. & $\begin{array}{l}\text { Hordeum vulgare } \\
\text { (Barley) }\end{array}$ & 2DE & $\begin{array}{l}\text { Differential proteomics for identification of proteins associated with } \\
\text { grain quality }\end{array}$ & Finnie, et al. [14] \\
\hline 2. & Magnolia seaboldii & 2DE & Comparative protein profiling at seed germination stage & Lu, et al. [29] \\
\hline 3. & $\begin{array}{l}\text { Hordeum vulgare } \\
\text { (Barley) }\end{array}$ & $2 \mathrm{DE}$ & $\begin{array}{l}\text { Study of proteins produced in response to biotic stress ( Fusarium } \\
\text { infection) during grain development }\end{array}$ & Trumper, et al. [30] \\
\hline 4. & Petunia & 2DE & $\begin{array}{l}\text { Differential expression studies of proteins associated with } \\
\text { anthocyanin }\end{array}$ & Prinsi, et al. [31] \\
\hline 5. & $\begin{array}{l}\text { Prunus persica } \\
\text { (Peach) }\end{array}$ & 2DE & $\begin{array}{l}\text { Mesocarp and leaf proteome study for understanding chilling stress } \\
\text { response }\end{array}$ & Almeida, et al. [32] \\
\hline 6. & Zea mays (Maize) & $2 \mathrm{DE}$ & Proteome analysis of mid-rib determining the size of leaf angle & Wang, et al. [33] \\
\hline 7. & Glycine max (Soybean) & $2 \mathrm{DE}$ & Analysis of proteins associated with seed filling & Hadjuch, et al. [34] \\
\hline 8. & $\begin{array}{l}\text { Citrus sinensis \& Citrus } \\
\text { grandis }\end{array}$ & $2 \mathrm{DE}$ & $\begin{array}{l}\text { Differential proteomics to demonstrate boron toxicity in two } \\
\text { species differing in boron tolerance }\end{array}$ & Sang, et al. [35] \\
\hline 9. & Brachypodium distachyon & 2DE-MALDI/TOF & Leaf and root proteome analysis in response to $\mathrm{H}_{2} \mathrm{O}_{2}$ stress & Bian, et al. [36] \\
\hline 10. & $\begin{array}{l}\text { Pisum sativum } \\
\text { (Pea) }\end{array}$ & 2D-DIGE & $\begin{array}{l}\text { Identification of proteins produced in response to Orobanche } \\
\text { crenata }\end{array}$ & Castellejo, et al. [37] \\
\hline 11. & $\begin{array}{l}\text { Hordeum vulgare } \\
\text { Barley }\end{array}$ & ICAT & $\begin{array}{l}\text { Detection of thioredoxin target disulfide in proteins released from } \\
\text { aleurone layer }\end{array}$ & Hagglund, et al. [92] \\
\hline 12. & $\begin{array}{l}\text { Solanum lycopersicon } \\
\text { (Tomato) }\end{array}$ & TMT & Detection of redox proteins responsive to biotic stress (P.syringae) & Parker, et al. [38] \\
\hline 13. & $\begin{array}{l}\text { Ricinus communis } \\
\text { (Castor bean) }\end{array}$ & ICPL \& ITRAQ & Analysis of proteins involved in development of endosperm & Nogueria, et al. [93] \\
\hline 14. & $\begin{array}{l}\text { Vitis vinefera } \\
\text { Grape }\end{array}$ & ITRAQ & $\begin{array}{l}\text { Analysis of mesocarp and endocarp proteins synthesized in } \\
\text { response to pathogen }\end{array}$ & $\begin{array}{l}\text { Melo-Braga, et al. } \\
{[26]}\end{array}$ \\
\hline 15. & Oryza sativa (Rice) & iTRAQ & Analysis of cold-responsive proteins & Neilson, et al. [94] \\
\hline 16. & Triticum aestivum (Wheat) & iTRAQ & Study of protein responses to biotic stresses (powdery mildew) & Fu, et al. [24] \\
\hline 17. & $\begin{array}{l}\text { Camellina sinensis } \\
\text { (Tea plant) }\end{array}$ & iTRAQ & $\begin{array}{l}\text { Differential protein studies concerned to chlorophyll content and } \\
\text { abnormal chloroplast development }\end{array}$ & Wang, et al. [39] \\
\hline 18. & $\begin{array}{l}\text { Nicotiana tabacum } \\
\text { (Tobacco) }\end{array}$ & iTRAQ & $\begin{array}{l}\text { Understanding TMV resistance mechanism by differential protein } \\
\text { analysis of susceptible and resistant strains }\end{array}$ & Wang, et al. [40] \\
\hline 19. & Glycine max (Soybean) & iTRAQ & Proteins and pathways associated with male sterility were revealed & Li, et al. [41] \\
\hline 20. & $\begin{array}{l}\text { Cucumis sativus } \\
\text { (Cucumber) }\end{array}$ & iTRAQ & $\begin{array}{l}\text { Identification of proteins produced in phloem sap in response to } \\
\text { salt stress }\end{array}$ & Fan, et al. [42] \\
\hline 21. & Arabidopsis & iTRAQ-OFFGEL & $\begin{array}{l}\text { Detection of proteins required for regulation of iron homeostasis } \\
\text { and transport mechanisms }\end{array}$ & Zargar, et al. [21] \\
\hline
\end{tabular}




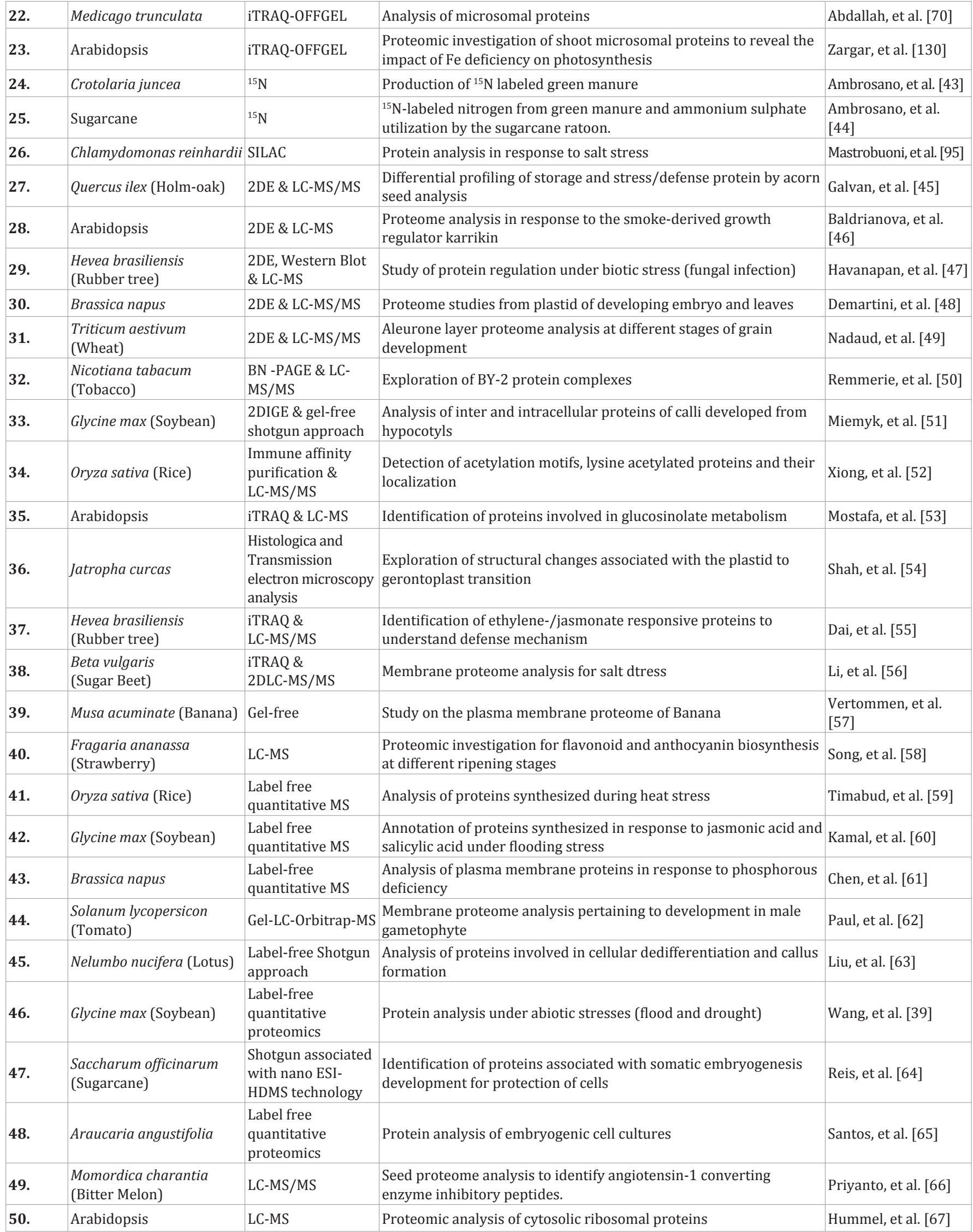


The curiosity to unravel the concealed mysteries of life and various processes involved in its sustenance inspired the researchers to understand the basic regulatory pathways of biological systems. In this regard, tremendous efforts have been made in the field of genomics, transcriptomics, proteomics, metabolomics and ionomics. We have confined this article to proteomics approach only. Initially, protein profiling and protein-protein interactions were performed to study the diverse proteins. Then the focus was shifted to proteome analysis by employing $2 \mathrm{DE}$ in the late $20^{\text {th }}$ century. Later, with advancements in technologies, gel-free proteomics strategies came into limelight that attempts to enumerate the functional dimension of proteins by employing more reliable and proficient tools for precise and accurate results. To date, huge numbers of entries have been made concerned to study of insects, worms, animals, human diseases studies [123-126]. These approaches have found wide applicability in the field of medicines for discovery of biomarkers and early disease diagnosis [127]. And evolutionary ecology studies [128]. As well. However, the field of plant proteomics is still in its infancy and needs to be explored due to presence of vast diverse proteins and metabolites. As mentioned above, there is no single strategy that can be considered selfsufficient to evaluate all the proteins. The detection of novel proteins and their dynamics requires combined efforts of modern technologies. The choice of a particular proteomic strategy depends on the biological question under consideration. Amendment in the employed scientific technologies, tools and databases is bound to render extremely informative facts concerned to metabolism. The sub-cellular proteome studies have been carried out in the past years [129]. Recently, the concept of proteome atlas has been introduced that emphasizes the need to integrate specific proteome studies to create a big picture of diverse proteins involved in metabolic and regulatory pathways [130]. The proteome analysis of different organelles at different developmental stages under varied environmental conditions will help to elucidate the metabolic regulations producing diverse proteins and metabolites. In-depth knowledge of these metabolic routes will expand our knowledge and assist in manipulation of key elements to produce desired results and development of superior genotypes having agronomic merit with biotic and abiotic stress tolerance. Thus, we can conclude that the incremental refinement in proteomic technologies and ongoing efforts of the researchers will facilitate unveiling the metabolic networks for deducing unexplored mechanisms and creating wealth of information.

\section{References}

1. Wilkins MR, Sanchez JC, Gooley AA, Appel RD, Humphery-Smith I, Hochstrasser DF et al.: Progress with proteome projects: why all proteins expressed by a genome should be identified and how to do it. Biotechnol Genet Eng Rev. 1996;13:19-50.

2. Tyers M, Mann M. From genomics to proteomics. Nature. 2003;422(6928):193-7.

3. Liebler DC. Introduction to Proteomics: Tools for the New Biology. Totowa, New Jersey Humana Press. Inc. 2002.

4. Chevalier F. Highlights on the capacities of "Gel-based" proteomics.

\section{Proteome Sci. 2010;8:23. Doi: 10.1186/1477-5956-8-23.}

5. Kamo M, Kawakami T, Miyatake N, Tsugita A: Separation and characterization of Arabidopsis thaliana proteins by two- dimensional gel electrophoresis. Electrophoresis. 1995;16(3):423-30

6. Santoni V, Rouquié D, Doumas P, Mansion M, Boutry M, Degand $\mathrm{H}$, et al. Use of a proteome strategy for tagging proteins present at the plasma membrane. Plant J. 1998;16(5):633-41.

7. Peltier JB, Friso G, Kalume DE, Roepstorff P, Nilsson F, Adamska I, et al. Proteomics of the chloroplast: systematic identification and targeting analysis of lumenal and peripheral thylakoid proteins. Plant Cell. 2000;12(3):319-41.

8. Kruft V, Eubel H, Jänsch L, Werhahn W, Braun HP. Proteomic approach to identify novel mitochondrial proteins in Arabidopsis. Plant Physiol. 2001;127(4):1694-710.

9. Chivasa S, Ndimba BK, Simon WJ, Robertson D, Yu XL, Knox JP, et al. Proteomic analysis of the Arabidopsis thaliana cell wall. Electrophoresis. 2002;23(11):1754-65.

10. Bae MS, Cho EJ, Choi EY, Park OK. Analysis of the Arabidopsis nuclear proteome and its response to cold stress. Plant J. 2003;36(5):652-63.

11. Borner GH, Lilley KS, Stevens TJ, Dupree P. Identification of glycosylphosphatidylinositol-anchored proteins in Arabidopsis. A proteomic and genomic analysis. Plant Physiol. 2003;132(2):568-77.

12. Porubleva L, Vander Velden K, Kothari S, Oliver DJ, Chitnis PR. The proteome of maize leaves: use of gene sequences and expressed sequence tag data for identification of proteins with peptide mass fingerprints. Electrophoresis. 2001;22(9):1724-38.

13. Gallardo K, Job C, Groot SP, Puype M, Demol H, Vandekerckhove J, et al. Proteomics of Arabidopsis Seed Germination. A Comparative Study of Wild-Type and Gibberellin-Deficient Seeds. Plant Physiol. 2002;129(2):823-37.

14. Finnie C, Melchior S, Roepstorff P, Svensson B. Proteome Analysis of Grain Filling and Seed Maturation in Barley. Plant Physiol. 2002;129(3):1308-19.

15. Bhushan D, Jaiswal DK, Ray D, Basu D, Datta A, Chakraborty S, et al. Dehydration-responsive reversible and irreversible changes in the extracellular matrix: Comparative proteomics of chickpea genotypes with contrasting tolerance. J Proteome Res. 2011;10(4):2027-46. Doi: $10.1021 /$ pr200010f.

16. Staudinger C, Mehmeti V, Turetschek R, Lyon D, Egelhofer V, Wienkoop S. Possible role of nutritional priming for early salt and drought stress responses in Medicago truncatula. Front Plant Sci. 2012;3:285. Doi: 10.3389/fpls.2012.00285.

17. Zadražnik T, Hollung K, Egge-Jacobsen W, Meglič V, Šuštar-Vozlič J, et al. Differential proteomic analysis of drought stress response in leaves of common bean (Phaseolus vulgaris L.). J Proteomics. 2013;78:254-72. Doi: 10.1016/j.jprot.2012.09.021.

18. Muneer S, Hakeem KR, Mohamed R, Lee JH. Cadmium toxicity induced alterations in the root proteome of green gram in contrasting response towards iron supplement. Int J Mol Sci. 2014;15(4):634355. Doi: 10.3390/ijms15046343.

19. Irar S, González EM, Arrese-Igor C, Marino D. A proteomic approach reveals new actors of nodule response to drought in split-root grown pea plants. Physiol Plant. 2014;152(4):634-45. Doi: 10.1111/ ppl.12214.

20. Swigonska S, Weidner S. Proteomic analysis of response to long- 
term continuous stress in roots of germinating soybean seeds. J Plant Physiol. 2013;170(5):470-9. Doi: 10.1016/j.jplph.2012.11.020

21. Zargar SM, Kurata R, Inaba S, Fukao Y. Unravelling the iron deficiency responsive proteome in Arabidopsis shoot by iTRAQ-OFF GEL approach. Plant Signal Behav. 2013;8(10): Doi: 10.4161/psb.26892.

22. Sato D, Akashi H, Sugimoto M, Tomita M, Soga T. Metabolomic profiling of there sponse of susceptible and resistant soybean strains to foxglove aphid, Aulacorthum solani. Kaltenbach. J Chromatogr B Analyt Technol Biomed Life Sci. 2013;925:95-103. Doi: 10.1016/j. jchromb.2013.02.036

23. Watson BS, Bedair MF, Urbanczyk-Wochniak E, Huhman DV, Yang DS, Allen SN, et al. Integrated metabolomics and transcriptomics reveal enhanced specialized metabolism in Medicago truncatula root Border Cells. Plant Physiol. 2015;167(4):1699-716. Doi: 10.1104/ pp.114.253054.

24. Fu Y, Zhang H, Mandal SN, Wang C, Chen C, Ji W, et al. Quantitative proteomics reveals the central changes of wheat in response to powdery mildew. J Proteomics. 2016;130:108-19. Doi: 10.1016/j. jprot.2015.09.006.

25. Kaffarnik FA, Jones AM, Rathjen JP, Peck SC. Effector proteins of the bacterial pathogen Pseudomonas syringae alter the extracellular proteome of the host plant, Arabidopsis thaliana. Mol Cell Proteomics. 2009;8(1):145-56. Doi: 10.1074/mcp.M800043-MCP200.

26. Melo-Braga MN, Verano-Braga T, León IR, Antonacci D, Nogueira FC, Thelen JJ, et al. Modulation of protein phosphorylation, glycosylation and acetylation in grape (Vitis vinifera) mesocarp and exocarp due to Lobesia botrana infection. Mol Cell Proteomics. 2012;11(10):945-56.

27. Marsh E, Alvarez S, Hicks LM, Barbazuk WB, Qiu W, Kovacs L, et al. Changes in protein abundance during powdery mildew infection of leaf tissues of Cabernet Sauvignon grapevine (Vitis vinifera L.) Proteomics. 2010;10(10):2057-64. Doi: 10.1002/pmic.200900712.

28. Fan J, Chen C, Yu Q, Brlansky RH, Li ZG, Gmitter FG Jr et al. Comparative iTRAQ proteome and transcriptome analyses of sweet orange infected by, 'Candidatus Liberibacter asiaticus'. Physiol Plant. 2011;143(3):235-45. Doi: 10.1111/j.1399-3054.2011.01502.x.

29. Lu XJ, Zhang XL, Mei M, Liu GL, Ma BB. Proteomic analysis of Magnolia sieboldii K. Koch seed germination. J Proteomics. 2016;133:76-85 Doi: 10.1016/j.jprot.2015.12.005.

30. Trümper C, Paffenholz K, Smit I, Kössler P, Karlovsky P, Braun HP, et al. Identification of regulated proteins in naked barley grains (Hordeum vulgare nudum) after Fusarium graminearum infection at different grain ripening stages. J Proteomics. 2016;133:86-92. Doi: 10.1016/j.jprot.2015.11.015.

31. Prinsi B, Negri AS, Quattrocchio FM, Koes RE, Espen L.Proteomics of red and white corolla limbs in petunia reveals a novel function of the anthocyanin regulator ANTHOCYANIN1 in determining flower longetivity. J Proteomics. 2016;131:38-47. doi: 10.1016/j. jprot.2015.10.008.

32. Almeida AM, Urra C, Moraga C, Jego M, Flores A, Meisel L, et al Proteomic analysis of a segregant population reveals candidate proteins linked to mealiness in peach. J Proteomics. 2016;131:71-81. doi: 10.1016/j.jprot.2015.10.011.

33. Wang N, Cao D, Gong F, Ku L, Chen Y, Wang W, et al. Differences in properties and proteomes of the midribs contribute to the size of the leaf angle in two near-isogenic maize lines. J Proteomics. 2015;128:113-22. Doi: 10.1016/j.jprot.2015.07.027.

34. Hajduch M, Ganapathy A, Stein JW, Thelen JJ. A systematic proteomic study of seed filling in soybean: establishment of high-resolution twodimensional reference maps, expression profiles, and an interactive proteome database. Plant Physiol. 2005;137(4):1397-419.

35. Sang W, Huang ZR, Qi YP, Yang LT, Guo P, Chen LS, et al. An investigation of boron-toxicity in leaves of two citrus species differing in boron-tolerance using comparative proteomics. J Proteomics. 2015;123:128-46. Doi: 10.1016/j.jprot.2015.04.007.

36. Bian YW, Lv DW, Cheng ZW, Gu AQ, Cao H, Yan YM, et al. Integrative proteome analysis of Brachypodium distachyon roots and leaves reveals a synergetic responsive network under $\mathrm{H}_{2} \mathrm{O}_{2}$ stress. J Proteomics. 2015;128:388-402. Doi: 10.1016/j.jprot.2015.08.020.

37. Castillejo MÁ, Fernández-Aparicio M, Rubiales D. Proteomic analysis by two dimensional in gel electrophoresis (2D DIGE) of the early response of Pisum sativum to Orobanche crenata. J Exp Bot. 2012;63(1):107-19. Doi: 10.1093/jxb/err246.

38. Parker J, Zhu N, Zhu M, Chen S. Profiling thiol redox proteome using isotope tagging mass pectrometry. J Vis Exp. 2012;(61). Pii: 3766. Doi: $10.3791 / 3766$.

39. Wang J, Wang XR, Zhou Q, Yang JM, Guo HX, Yang LJ, et al. iTRAQ protein profile analysis provides integrated insight into mechanism of tolerance to TMV in Tobacco (Nicotiana tabacum). J Proteomics. 2016;132:21-30. Doi: 10.1016/j.jprot.2015.11.009.

40. Wang L, Cao H, Chen C, Yue C, Hao X, Yang Y, et al. Complementary transcriptomic and proteomic analyses of a chlorophyll-deficient tea plant cultivar reveal multiple metabolic pathway changes. J Proteomics. 2016;130:160-9. Doi: 10.1016/j.jprot.2015.08.019.

41. Li J, Ding X, Han S, He T, Zhang H, Yang L, et al. Differential proteomics analysis to identify proteins and pathways associated with male sterility of soybean using iTRAQ-based strategy. J Proteomics. 2016;138:72-82. Doi: 10.1016/j.jprot.2016.02.017.

42. Fan $\mathrm{H}, \mathrm{Xu} \mathrm{Y}, \mathrm{Du} \mathrm{C}, \mathrm{Wu} \mathrm{X}$. Phloem sap proteome studied by iTRAQ provides integrated insight into salinity response mechanisms in cucumber plants. J Proteomics. 2015;125:54-67. doi: 10.1016/j. jprot.2015.05.001.

43. Ambrosano EJ, Trivelin PCO, Cantarella H, et al. Nitrogen-15 labelling of Crotolaria juncea green manure. Scientia Agricola. 2003;60(1):181184.

44. Ambrasano EJ, Trivelin PCO, Cantarella H, Ambrasano GMB, Schammass EA, Muraoka T, Rossi F. ${ }^{15} \mathrm{~N}$-labeled nitrogen from green manure and ammonium sulphate utilization by the sugarcane ratoon. Scientia Agricola. 2011;68(3):361-368.

45. Valero Galván J, Valledor L, Navarro Cerrillo RM, Gil Pelegrín E, Jorrín-Novo JV. Studies of variability in Holm oak (Quercus ilex subsp. Ballota [Desf.] Samp.) Through acorn protein profile analysis. J Proteomics. 2011;74(8):1244-55. Doi: 10.1016/j.jprot.2011.05.003.

46. Baldrianová J, Černý M, Novák J, Jedelský PL, Divíšková E, Brzobohatý $\mathrm{B}$, et al. Arabidopsis proteome responses to the smoke-derived growth regulator karrikin. J Proteomics. 2015;120:7-20. Doi: 10.1016/j.jprot.2015.02.011.

47. Havanapan PO, Bourchookarn A, Ketterman AJ, Krittanai C. Comparative proteome analysis of rubber latex serum from pathogenic fungi tolerant and susceptible rubber tree (Hevea brasiliensis). J Proteomics. 2016;131:82-92. Doi: 10.1016/j. jprot.2015.10.014.

48. Demartini DR, Jain R, Agrawal G, Thelen JJ. Proteomic comparison of plastids from developing embryos and leaves of Brassica napus. J Proteome Res. 2011;10(5):2226-37. doi: 10.1021/pr101047y. 
49. Nadaud I, Tasleem-Tahir A, Chateigner-Boutin AL, Chambon C, Viala D, Branlard G et al. Proteome evolution of wheat (Triticum aestivum L.) aleurone layer at fifteen stages of grain development. J Proteomics. 2015;123:29-41. doi: 10.1016/j.jprot.2015.03.008

50. Remmerie N, De Vijlder T, Valkenborg D, Laukens K, Smets K, Vreeken $\mathrm{J}$, et al. Unravelling tobacco BY-2 protein complexes with BN PAGE/ LC-MS/MS and clustering methods. J Proteomics. 2011;74(8):120117. Doi: $10.1016 /$ j.jprot.2011.03.023.

51. Miernyk JA, Jett AA, Johnston ML. Analysis of soybean tissue culture protein dynamics using difference gel electrophoresis. J Proteomics. 2016;130:56-64. Doi: 10.1016/j.jprot.2015.08.023.

52. Xiong Y, Peng X, Cheng Z, Liu W, Wang GL. A comprehensive catalog of the lysine-acetylation targets in rice (Oryza sativa) based on proteomic analyses. J Proteomics. 2016;138:20-9. Doi: 10.1016/j. jprot.2016.01.019.

53. Mostafa I, Zhu N, Yoo MJ, Balmant KM, Misra BB, Dufresne C, et al. New nodes and edges in the glucosinolate molecular network revealed by proteomics and metabolomics of Arabidopsis myb28/29 and cyp79B2/B3 glucosinolate mutants. J Proteomics. 2016;138:1-19. Doi: 10.1016/j.jprot.2016.02.012

54. Shah M, Soares EL, Lima ML, Pinheiro CB, Soares AA, Domont GB, et al. Deep proteome analysis of gerontoplasts from the inner integument of developing seeds of Jatropha curcas. J Proteomics. 2016. Pii: S1874-3919(16)30047-1. Doi: 10.1016/j.jprot.2016.02.025.

55. Dai L, Kang G, Nie Z, Li Y, Zeng R.Comparative proteomic analysis of latex from Hevea brasiliensis treated with Ethrel and methyl jasmonate using iTRAQ-coupled two-dimensional LC-MS/MS. J Proteomics. 2016;132:167-75. doi: 10.1016/j.jprot.2015.11.012.

56. Li H, Pan Y, Zhang Y, Wu C, Ma C, Yu B, et al. Salt stress response of membrane proteome of sugar beet monosomic addition line M14. J Proteomics. 2015;127(Pt A):18-33. Doi: 10.1016/j.jprot.2015.03.025.

57. Vertommen A, Møller AL, Cordewener JH, Swennen R, Panis B, Finnie C, et al. A workflow for peptide-based proteomics in a poorly sequenced plant: A case study on the plasma membrane proteome of banana. J Proteomics. 2011;74(8):1218-29. doi: 10.1016/j. jprot.2011.02.008

58. Song J, Du L, Li L, Kalt W, Palmer LC, Fillmore S, et al. Quantitative changes in proteins responsible for flavonoid and anthocyanin biosynthesis in strawberry fruit at different ripening stages: A targeted quantitative proteomic investigation employing multiple reaction monitoring. J Proteomics. 2015;122:1-10. doi: 10.1016/j. jprot.2015.03.017.

59. Timabud T, Yin X, Pongdontri P, Komatsu S. Gel-free/label-free proteomic analysis of developing rice grains under heat stress. J Proteomics. 2016;133:1-19. Doi: 10.1016/j.jprot.2015.12.003.

60. Kamal AH, Komatsu S. Jasmonic acid induced protein response to biophoton emissions and flooding stress in soybean. J Proteomics. 2016;133:33-47. Doi: 10.1016/j.jprot.2015.12.004

61. Chen S, Luo Y, Ding G, Xu F. Comparative analysis of Brassica napus plasma membrane proteins under phosphorus deficiency using labelfree and MaxQuant-based proteomics approaches. J Proteomics. 2016;133:144-52. Doi: 10.1016/j.jprot.2015.12.020.

62. Paul P, Chaturvedi P, Selymesi M, Ghatak A, Mesihovic A, Scharf KD, et al. The membrane proteome of male gametophyte in Solanum lycopersicum. J Proteomics. 2016;131:48-60. Doi: 10.1016/j. jprot.2015.10.009.

63. Liu Y, Chaturvedi P, Fu J, Cai Q, Weckwerth W, Yang P, et al. Induction and quantitative proteomic analysis of cell dedifferentiation during callus formation of lotus (Nelumbo nucifera Gaertn. spp. Baijianlian). J Proteomics. 2016;131:61-70. doi: 10.1016/j.jprot.2015.10.010.

64. Reis RS, Vale Ede M, Heringer AS, Santa-Catarina C, Silveira V. Putrescine induces somatic embryo development and proteomic changes in embryogenic callus of sugarcane. J Proteomics. 2016;130:170-9. Doi: 10.1016/j.jprot.2015.09.029.

65. dos Santos AL, Elbl P, Navarro BV, de Oliveira LF, Salvato F, Balbuena TS, et al. Quantitative proteomic analysis of Araucaria angustifolia (Bertol.) Kuntze cell lines with contrasting embryogenic potential. J Proteomics. 2016;130:180-9. Doi: 10.1016/j.jprot.2015.09.027.

66. Priyanto AD, Doerksen RJ, Chang CI, Sung WC, Widjanarko SB, Kusnadi J, et al. Screening, discovery, and characterization of angiotensin-1 converting enzyme inhibitory peptides derived from proteolytic hydrolysate of bitter melon seed proteins. J Proteomics. 2015;128:424-35. doi: 10.1016/j.jprot.2015.08.018.

67. Hummel M, Dobrenel T, Cordewener JJ, Davanture M, Meyer C, Smeekens SJ, et al. Proteomic LC-MS analysis of Arabidopsis cytosolic ribosomes: Identification of ribosomal protein paralogs and re-annotation of the ribosomal protein genes. J Proteomics. 2015;128:436-49. Doi: 10.1016/j.jprot.2015.07.004.

68. O'Farrell PH. High resolution two-dimensional electrophoresis of proteins. J Biol Chem. 1975;250(10):4007-21.

69. Smithies O. How it all began: A personal history of gel electrophoresis. Methods Mol Biol. 2012;869:1-21. Doi: 10.1007/978-1-61779-8214_1.

70. Abdallah C, Dumas-Gaudot E, Renaut J, Sergeant K. Gel-Based and Gel-Free Quantitative Proteomics Approaches at a Glance. Int J Plant Genomics. 2012;2012:494572. doi: 10.1155/2012/494572.

71. Weber K, Osborn M. The reliability of molecular weight determinations by dodecyl sulfate-polyacrylamide gel electrophoresis. J Biol Chem. 1969;244(16):4406-12.

72. Switzer RC 3rd, Merril CR, Shifrin S. A highly sensitive silver stain for detecting proteins and peptides in polyacrylamide gels. Anal. Anal Biochem. 1979;98(1):231-7.

73. Deracinois B, Flahaut C, Duban-Deweer S, Karamanos Y. Comparative and Quantitative Global Proteomics Approaches: An Overview Proteomes. 2013;1:180-218. Doi: 10.3390/ proteomes 1030180.

74. Liebler DC. Introduction to Proteomics: Tools for the New Biology. Totowa, New Jersey Humana Press. Inc. 2002.

75. Zhou S, Bailey MJ, Dunn MJ, Preedy VR, Emery PW. A quantitative investigation into the losses of proteins at different stages of a two-dimensional gel electrophoresis procedure. Proteomics. 2005;5(11):2739-47.

76. Lilley KS, Razzaq A, Dupree P. Two-dimensional gel electrophoresis: recent advances in sample preparation, detection and quantitation. Curr Opin Chem Biol. 2002;6(1):46-50.

77. Gygi SP, Corthals GL, Zhang Y, Rochon Y, Aebersold R. Evaluation of two-dimensional gel electrophoresis- based proteome analysis technology. Proc Natl Acad Sci U S A. 2000;97(17):9390-5.

78. Borner GH, Lilley KS, Stevens TJ, Dupree P. Identification of glycosyl phosphatidylinositol-anchored proteins in Arabidopsis. A proteomic and genomic analysis. Plant Physiol. 2003;132(2):568-77.

79. Unlü M, Morgan ME, Minden JS. Difference gel electrophoresis: A single gel method for detecting changes in protein extracts. Electrophoresis. 1997;18(11):2071-7. 
80. Khatoon A, Rehman S, Hiraga S, Makino T, Komatsu S. Organspecific proteomics analysis for identification of response mechanism in soybean seedlings under flooding stress. J Proteomics. 2012;75(18):5706-23. Doi: 10.1016/j.jprot.2012.07.031.

81. Salavati A, Khatoon A, Nanjo Y, Komatsu S. Analysis of proteomic changes in roots of soybean seedlings during recovery after flooding J Proteomics. 2012;75(3):878-93. Doi: 10.1016/j.jprot.2011.10.002.

82. Schenkluhn L, Hohnjec N, Niehaus K, Schmitz U, Colditz F. Differentia gel electrophoresis (DIGE) to quantitatively monitor early symbiosisand pathogenesis-induced changes of the Medicago truncatula root proteome. J Proteomics. 2010;73(4):753-68. doi: 10.1016/j. jprot.2009.10.009.

83. Sergeant K, Spiess N, Renaut J, Wilhelm E, Hausman JF. One dry summer: a leaf proteome study on the response of oak to drought exposure. J Proteomics. 2011;74(8):1385-95. Doi: 10.1016/j. jprot.2011.03.011

84. Li T, Xu SL, Oses-Prieto JA, Putil S, Xu P, Wang RJ, et al. Proteomics analysis reveals post-translational mechanisms for cold-induced metabolic changes in Arabidopsis. Mol Plant. 2011;4(2):361-74. doi: $10.1093 / \mathrm{mp} / \mathrm{ssq078.}$

85. Fu C, Hu J, Liu T, Ago T, Sadoshima J, Li H. Quantitative Analysis of Redox-sensitive Proteome with DIGE and ICAT. J Proteome Res 2008;7(9):3789-802. doi: 10.1021/pr800233r

86. Braisted JC, Kuntumalla S, Vogel C, Marcotte EM, Rodrigues AR, Wang $\mathrm{R}$, et al. The APEX Quantitative Proteomics Tool: Generating protein quantitation estimates from LC-MS/MS proteomics results. BMC Bioinformatics. 2008;9:529. Doi: 10.1186/1471-2105-9-529.

87. Charro N, Hood BL, Faria D, Pacheco P, Azevedo P, Lopes C, et al. Serum proteomics signature of cystic fibrosis patients: a complementary 2-DE and LC-MS/MS approach. J Proteomics. 2011;74(1):110-26. doi: 10.1016/j.jprot.2010.10.001.

88. Finamore F, Pieroni L, Ronci M, Marzano V, Mortera SL, Romano M, et al. Proteomics investigation of human platelets by shotgun nUPLC MSE and 2DE experimental strategies: a comparative study. Blood Transfus. 2010;8 Suppl 3:s140-8. doi: 10.2450/2010.021S

89. Syahir a, Usui K, Tomizaki K, Kajikawa K, Mihara H. Label and Labelfree Detection Techniques for Protein Microarrays. Microarrays 2015;4:228-244.

90. Bantscheff M, Lemeer S, Savitski MM, Kuster B. Quantitative mass spectrometry in proteomics: a critical review. Anal Bioanal Chem. 2012;404(4):939-65. Doi: 10.1007/s00216-012-6203-4.

91. Yang Y, Qiang X, Owsiany K, Zhang S, Thannhauser TW, Li L, et al. Evaluation of different multidimensional LC- MS/MS pipelines for isobaric tags for relative and absolute quantitation (iTRAQ)-based proteomic analysis of potato tubers in response to cold storage. J Proteome Res. 2011;10(10):4647-60. Doi: 10.1021/pr200455s.

92. Hägglund P, Bunkenborg J, Yang F, Harder LM, Finnie C, Svensson B, et al. Identification of thioredoxin target disulfides in proteins released from barley aleurone layers. J Proteomics. 2010;73(6):1133-6. doi: 10.1016/j.jprot.2010.01.007.

93. Nogueira FC, Palmisano G, Schwämmle V, Campos FA, Larsen MR, Domont GB, et al. Performance of isobaric and isotopic labeling in quantitative plant proteomics. J Proteome Res. 2012;11(5):3046-52. Doi: $10.1021 / p r 300192 f$.

94. Neilson KA, Mariani M, Haynes PA. Quantitative proteomic analysis of cold-responsive proteins in rice. Proteomics. 2011;11(9):1696-706. Doi: $10.1002 /$ pmic.201000727.
95. Mastrobuoni G, Irgang S, Pietzke M, Assmus HE, Wenzel M, Schulze $\mathrm{WX}$, et al. Proteome dynamics and early salt stress response of the photosynthetic organism Chlamydomonas reinhardtii. BMC Genomics. 2012;13:215.

96. Gygi SP, Rochon Y, Franza BR, Aebersold R. Correlation between protein and mRNA abundance in yeast. Mol Cell Biol. 1999;19(3):1720-30.

97. Qiu Y, Sousa EA, Hewick RM, Wang JH. Acid-Labile isotope-coded extractants: A class of reagents for quantitative mass spectrometric analysis of complex protein mixtures. Anal Chem. 2002;74(19):496979.

98. Bottari P, Aebersold R, Turecek F, Gelb MH. Design and synthesis of visible isotope-coded affinity tags for the absolute quantification of specific proteins in complex mixtures. Bioconjug Chem. 2004;15(2):380-8.

99. Schmidt A, Kellermann J, Lottspeich F. A novel strategy for quantitative proteomics using isotope-coded protein labels. Proteomics. 2005;5(1):4-15.

100. Leroy B, Rosier C, Erculisse V, Leys N, Mergeay M, Wattiez R, et al. Differential proteomic analysis using isotope- coded proteinlabeling strategies: comparison, improve- ments and application to simulated microgravity effect on Cupriavidus metallidurans $\mathrm{CH} 34$. Proteomics. 2010;10(12):2281-91. doi: 10.1002/pmic.200900286.

101. Lottspeich F, Kellermann J.ICPL labeling strategies for proteome research. Method. Methods Mol Biol. 2011;753:55-64. Doi: 10.1007/978-1-61779-148-2_4.

102. Mann M, Kulak NA, Nagaraj N, Cox J. The coming age of complete, accurate, and ubiquitous proteomes. Mol Cell. 2013;49(4):583-90. Doi: 10.1016/j.molcel.2013.01.029.

103. Ross PL, Huang YN, Marchese JN, Williamson B, Parker K, Hattan S, et al. Multiplexed protein quantitation in Saccharomyces cerevisiae using amine-reactive isobaric tagging reagents. Mol Cell Proteomics. 2004;3(12):1154-69.

104. Dayon L, Hainard A, Licker V, Turck N, Kuhn K, Hochstrasser DF, et al. Relative quantification of proteins in human cerebrospinal fluids by MS/MS using 6-plex isobaric tags. Anal Chem. 2008;80(8):292131. doi: 10.1021/ac702422x

105. Niles R, Witkowska HE, Allen S, Hall SC, Fisher SJ, Hardt M et al. Acid-Catalyzed oxygen-18 labeling of peptides. Anal Chem. 2009;81(7):2804-9. doi: 10.1021/ac802484d.

106. Goodlett DR, Keller A, Watts JD, Newitt R, Yi EC, Purvine S, et al. Differential stable isotope labeling of peptides for quantitation and de novo sequence derivation. Rapid Commun Mass Spectrom. 2001;15(14):1214-21.

107. Ong SE, Blagoev B, Kratchmarova I, Kristensen DB, Steen H, Pandey A, et al. Stable isotope labeling by amino acids in cell culture, SILAC, as a simple and accurate approach to expression proteomics. Mol Cell Proteomics. 2002;1(5):376-86.

108. Yates JR, Ruse CI, Nakorchevsky A. Proteomics by mass spectrometry: approaches, advances, and applications. Annu Rev Biomed Eng. 2009;11:49-79. doi: 10.1146/annurev-bioeng-061008-124934.

109. Ong SE, Mittler G, Mann M. Identifying and quantifying in vivo methylation sites by heavy methyl SILAC. Nat Methods. 2004;1(2):119-26.

110. Ishihama Y, Oda Y, Tabata T, Sato T, Nagasu T, Rappsilber J, et al. Exponentially modified protein abundance index (emPAI) for estimation of absolute protein amount in proteomics by the 
number of sequenced peptides per protein. Mol Cell Proteomics 2005;4(9):1265-72

111. Chelius D, Bondarenko PV. Quantitative profiling of proteins in complex mixtures using liquid chromatography and mass spectrometry. J Proteome Res. 2002;1(4):317-23.

112. Liu H, Sadygov RG, Yates JR 3rd. A model for random sampling and estimation of relative protein abundance in shotgun proteomics. Anal Chem. 2004;76(14):4193-201.

113. Eng JK, McCormack AL, Yates JR. An approach to correlate Tandem Mass Spectral Data of peptides with amino acid sequences in a protein database. J Am Soc Mass Spectrom. 1994;5(11):976-89. doi: 10.1016/1044-0305(94)80016-2.

114. Wang M1, You J, Bemis KG, Tegeler TJ, Brown DP. Label-Free mass spectrometry-based protein quantification technologies in proteomic analysis. Brief Funct Genomic Proteomic. 200;7(5):32939. doi: 10.1093/bfgp/eln031.

115. Strittmatter EF, Ferguson PL, Tang K, Smith RD. Proteome analyses using accurate mass and elution time peptide tags with capillary LC time-of-flight mass spectrometry. J Am Soc Mass Spectrom. 2003;14(9):980-91.

116. Zimmer JS, Monroe ME, Qian WJ, Smith RD. Advances in Proteomics Data Analysis and Display Using an Accurate Mass and Time Tag Approach. Mass Spectrom Rev. 2006;25(3):450-82.

117. Zhang B, VerBerkmoes NC, Langston MA, Uberbacher E, Hettich RL, Samatova NF et al. Detecting differential and correlated protein expression in label- free shotgun proteomics. J Proteome Res. 2006;5(11):2909-18.

118. Rappsilber J, Ryder U, Lamond AI, Mann M. Large-Scale proteomic analysis of the human spliceosome. Genome Res. 2002;12(8):123145.

119. Lu P, Vogel C, Wang R, Yao X, Marcotte EM. Absolute protein expression profiling estimates the relative contributions of transcriptional and translational regulation. Nat Biotechnol. 2007;25(1):117-24

120. Braisted JC, Kuntumalla S, Vogel C, Marcotte EM, Rodrigues AR, Wang R, et al. The APEX Quantitative Proteomics Tool: Generating protein quantitation estimates from LC-MS/MS proteomics results. BMC Bioinformatics. 2008;9:529. doi: 10.1186/1471-2105-9-529.

121. Beynon RJ, Doherty MK, Pratt JM, Gaskell SJ. Multiplexed absolute quantification in proteomics using artificial QCAT proteins of concatenated signature peptides. Nat Methods. 2005;2(8):587-9.

122. Silva JC, Denny R, Dorschel CA, Gorenstein M, Kass IJ, Li GZ, et al. Quantitative proteomic analysis by accurate mass retention time pairs. Anal Chem. 2005;77(7):2187-200.

123. Cao X, Fu Z, Zhang M, Han Y, Han H, Han Q, et al. iTRAQ-based comparative proteomic analysis of excretory-secretory proteins of schistosomula and adult worms of Schistosoma japonicum. J Proteomics. 2016;138:30-9. doi: 10.1016/j.jprot.2016.02.015

124. Brandi J, Pozza ED, Dando I, Biondani G, Robotti E, Jenkins R, et al. Secretome protein signature of human pancreatic cancer stem-like cells. J Proteomics. 2016;136:1-12. doi: 10.1016/j.jprot.2016.01.017.

125. Bruschi M, Santucci L, Ravera S, Candiano G, Bartolucci M, Calzia $D$, et al. Human urinary exosome proteome unveils its aerobic respiratory ability. J Proteomics. 2016;136:25-34. doi: 10.1016/j. jprot.2016.02.001.

126. Borges MH, Figueiredo SG, Leprevost FV, De Lima ME, Cordeiro Mdo N, Diniz MR, et al. Venomous extract protein profile of Brazilian tarantula Grammostola iheringi: searching for potential biotechnological applications. J Proteomics. 2016;136:35-47. doi: 10.1016/j.jprot.2016.01.013

127. Khan A, Khan AU. Biomarker Discovery and Drug Development: A Proteomics Approach. J Proteomics Bio inform. 2012;5:3.

128. Baer B, Millar AH. Proteomics in evolutionary ecology. J Proteomics. 2016;135:4-11. doi: 10.1016/j.jprot.2015.09.031.

129. Rossignol M, Analysis of the plant proteome. Current Opinion in Biotechnology. 2001;12(2): 131-134.

130. Zargar SM, Kurata R, Inaba S, Oikawa A, Fukui R, Ogata Y, et al. Quantitative proteomics of Arabidopsis shoot microsomal proteins reveals a cross-talk between excess zinc and iron deficiency. Proteomics. 2015;15(7):1196-201. doi: 10.1002/pmic.201400467. 